\title{
A Study of Maternal Mortality and Midwifery on the Isle of Man, 1882 to 1961
}

\author{
C G PANTIN*
}

\section{Introduction}

This study is based on the records of the women who died as the result of childbirth between 1 January 1882 and 31 December 1961 and were registered in the Isle of Man Registers of Death. It suggests that during the early part of this century, when births still took place in the mothers' homes and doctors had started to intervene during deliveries, Manx women would have increased their chances of surviving childbirth if, instead of choosing a doctor as their birth-attendant, they had chosen a midwife, although most of these had had no formal training.

While this study was in progress Dr Irvine Loudon's seminal work Death in childbirth was published. ${ }^{1}$ His book became an indispensable source of information, as Loudon investigates the development of midwifery and the changes in maternal mortality throughout most of the western world between the years 1800 and 1950 . It was found that the findings of the two studies could be reconciled only if it was assumed that the activities of the doctors in many of the countries studied by Loudon had increased the number of maternal deaths when, in their efforts to ameliorate the lot of parturient women, they took over the conduct of childbirth from the midwives.

\section{Establishing the Data}

The Isle of Man is situated in the middle of the Irish Sea and is nowhere less than 16 miles from one of the surrounding islands. The resident population numbered 53,558 in 1881 and 48,153 in 1961. All residents live within 20 miles of the largest town, Douglas, where in May 1927 an eleven-bedded maternity home was opened. It was named the Jane Crookall Maternity Home after the wife of the donor and it was replaced by a purposebuilt maternity home with the same name in 1939. The new building was designed to

*C G Pantin, OBE, MA, MD, FRCPath, 5 Saddle Mews, Castletown Road, Douglas, Isle of Man IM2 1 JA.

It will be clear from the text that I rely heavily on Dr Loudon's book for background and I am most grateful for his advice and encouragement. The study was made possible by the conscientious work of scores of registrars in the scattered districts of the Isle of Man. I am also indebted to Mr Peter Curtis, the Chief Registrar, for allowing access to the Registers of Death and to Mr John Taylor, Registrar in the Douglas Registry, and to his Deputy and successor,
Mrs Susan Cain, for their untiring patience and courtesy when asked to produce the Registers. I am grateful to Miss Ann Harrison, the Government Archivist, for finding the registers of the midwives of the Jane Crookall Maternity Home and to the midwives who kept the registers. My thanks go to Mrs Anne Seaton for correcting the punctuation and synesis of the text and to Dr Milling.

\footnotetext{
${ }^{1}$ Irvine Loudon, Death in childbirth: an international study of maternal care and maternal mortality 1800-1950, Oxford, Clarendon Press, 1992.
} 


\section{G Pantin}

accommodate 21 maternity cases at any one time. By 196190 per cent of the deliveries on the Island were taking place in the Home.

The Island is not part of the United Kingdom, being self-governing except for foreign affairs. Its demographic records have been published locally since 1880 as The Chief Registrar's annual report and statistical review of births, marriages and deaths in the Isle of Man (hereinafter called the Chief Registrars' annual reports or the Annual reports). The doctors who complete the Death Certificates initiate the collection of the mortality statistics. The registrars enter the data on each Death Certificate into the Registers of Death, and they use the cause of death given on the Certificate to classify the case: each death is entered in the appropriate place on a list of the causes of death received from the Registrar General's Office in the United Kingdom. Since 1911 this list has been based on the Manual of the International statistical classification of diseases and its revisions. At the end of each year since 1879 the Chief Registrars of the Isle of Man have consolidated the classified lists received from the registrars into tables which are included in their Annual reports. One set of tables shows both the cause of death and the district where the death occurred and, beginning in 1924, another set of tables shows the cause of death and the age at which the person died. The Chief Registrars have also included summaries based on the tables in which they state, inter alia, the number of mothers who had died as the result of pregnancy and childbirth during the year which they were recording.

Dr Loudon warns against accepting without question the figures given in the summaries of annual reports and quotes from Tandy's study of the international comparability of maternal mortality rates: "The essential point was the need to measure, evaluate, and take

Table 1

The differences between the number of maternal deaths recorded as occurring on the Isle of Man in the summaries and in the tables in the Chief Registrars' Annual reports in each of the 16 quinquennia following 1881.

The number of maternal deaths (abortions excluded) recorded in:

The Chief Registrars' annual reports

\begin{tabular}{lllr}
$\begin{array}{l}\text { Five-year } \\
\text { Period }\end{array}$ & Summaries & Cause of Discrepancy & Tables \\
\cline { 2 - 4 } $1882-1886$ & 42 & 2 cases missed out 1884 & 44 \\
$1887-1891$ & 34 & & 34 \\
$1892-1896$ & 37 & 1 P.fvr missed out 1895 & 38 \\
$1897-1901$ & 33 & & 33 \\
$1902-1906$ & 21 & 2 cases missed out 1908 & 21 \\
$1907-1911$ & 16 & & 18 \\
$1912-1916$ & 17 & 6 P.fvr missed out & 17 \\
$1917-1921$ & 15 & 12 neonates included, 1 P.fvr missed & 21 \\
$1922-1926$ & 27 & & 26 \\
$1927-1931$ & 19 & & 6 \\
$1932-1936$ & 10 & 6 cases missed out & 10 \\
$1937-1941$ & 12 & No discrepanies & 8 \\
$1942-1946$ & 2 & & \\
$1947-1961$ & & &
\end{tabular}


into account all possible sources of statistical distortion." 2 When the contents of the Chief Registrars' summaries were compared with the data in the tables in their Annual reports, discrepancies were found. The Chief Registrars sometimes omitted from their summaries cases which had been recorded as maternal deaths in the tables, and during the years between 1923 and 1932 they had included neonatal deaths under the heading 'Deaths from Pregnancy and Childbirth'. These discrepancies are set out in Table 1. Here, as throughout the study, the quinquennium is used as the unit of time.

The origin of these errors may lie in the lists of the causes of death received from the United Kingdom. In 1882 the registrars were required to enter deaths from puerperal fever under 'Zymotic Diseases' and all other deaths due to parturition in a separate section entitled 'Constitutional Diseases'. In 1883 William Ogle, who had succeeded Farr as compiler of extracts at the General Register Office, introduced a new nosology. This maintained the separation: puerperal fever was kept in Class I, 'Miasmic Diseases' among the 'Septic Diseases', and the other diseases of parturition were located in Class IV, 'Constitutional Diseases'. When this list of diseases was changed in 1902, following the first revision of the Manual of the international statistical classification of diseases, phlegmasia alba dolens joined puerperal fever in a group under 'A-General Diseases', while the remaining causes of maternal deaths were located under 'B-Local Diseases'.

Maternal deaths continued to be separately recorded in this way until 1922. In 1923, following the third revision of the Manual of the international statistical classification of diseases, the layout of the list of diseases received from the Registrar General's Office changed radically. There were no headings to show where major categories of disease were to go and there was little attempt at grouping. For the next nine years the registrars were invited to enter maternal deaths into a list of causes which ran uninterruptedly:

Diseases of prostate and male genital organs

Diseases of female genital organs (non-venereal)

Puerperal sepsis

Other causes incident to childbirth

Accident or injury at birth

Congenital malformations

Premature birth

Confusion due to the juxtaposition in the list of the two causes of death, 'Other causes incident to childbirth' relating to the death of mothers in childbirth and 'Accident or injury at birth' against which neonatal deaths should have been entered, may be the reason for the misplacing between 1923 and 1932 of 14 neonatal deaths. These were detected because the age of the putative mothers, entered against 'Other causes incident to childbirth', was given as under one year. The removal of these misplaced deaths reduces the number of mothers recorded as dying from 19 to 6 during the five years 1927 to 1931 and reveals the rapidity of the fall in the maternal mortality after the opening of the maternity home.

The preceding rise in the maternal deaths might have been an artefact due to the inclusion of neonates among maternal deaths in the Annual reports before 1924, the year when the recording of the age at which each mother died began. The Registers of Death

2 Ibid., p. 21. 


\section{G Pantin}

revealed that the number of maternal deaths listed in the years 1917 to 1923 was the same as that recorded in the Annual reports, leaving no deficiency that might have been filled by misplaced neonates.

\section{Searching the Registers of Death}

The Registers of Death were also searched from 1882 to 1961 for women aged 15 to 50 in whom parturition or its synonyms are mentioned among the causes of death. The Chief Registrars give in their Annual reports the district in which each maternal death had been reported; this made it less likely that maternal deaths would be missed when the Registers of Death for a district were searched.

The Registers of Death had already been searched when Loudon's book was published with its warning of the existence of hidden cases: maternal deaths in which any reference to pregnancy and childbirth had been omitted from the death certificate. On five occasions when searching the Registers for maternal deaths which, according to the tables in the Chief Registrars' annual reports, should have been recorded in a particular district, I had been unable to find them. The concept of hidden cases provided a possible explanation for this discrepancy: a Manx registrar would have known much of what was going on in his district and when someone's unmarried daughter died in childbirth and he received a notification of the death which, to lessen the embarrassment of the parents, did not mention pregnancy, he might well have entered the cause of death as it had been given into his Register but have entered the death on the list of causes of death as a maternal death. I decided to repeat the search while casting a more critical eye on the causes of death given for all women dying between the ages of 15 and 45. In the course of this search four of the five missing cases were found - the fifth being an abortion-and four other hidden cases came to light.

As a result of the two searches, 355 maternal deaths which had occurred on the Isle of Man between the beginning of 1882 and the end of 1961 were available for study, and during the second search the opportunity was taken to extract as much data as possible about them. This information appears in Appendix A. The 355 maternal deaths do not include abortions. The number of deaths due to abortions registered in each quinquennium is recorded in Appendix A but, otherwise, these deaths are ignored because they are very often hidden in the Registers of Death and they are not relevant in a study of midwifery. Deaths deemed to be due to an associated disease are included in Appendix A. In Table 2 the numbers of maternal deaths recorded in the Registers of Death are compared with the numbers given in the Annual reports for the 16 quinquennia following 1881. (The inclusion of neonates among the maternal deaths in the Chief Registrars' annual reports between 1923 and 1932 was discovered by an internal examination of the reports. Access to the Registers of Death was sought only after the errors had been found. Thus the data in Table 2 supports Loudon's belief that the figures in Registrar Generals' annual reports are a reliable source of information provided time is taken to search each report thoroughly. ${ }^{3}$ )

Unless it is stated otherwise, only direct maternal deaths, (b) in Table 2, are considered in the remainder of this paper.

\footnotetext{
${ }^{3}$ Ibid., p. 527
} 


\section{Table 2}

Comparing the total number of maternal deaths (a) and the number of direct maternal deaths (b) found in the Registers of Death in each of the 16 quinquennia following 1881 with the number of maternal deaths recorded in the Tables (c) and the Summaries (d) in the Chief Registrars' annual reports on the Isle of Man.

The number of maternal deaths (abortions excluded) recorded in:

Registers of Death

\begin{tabular}{lcccc} 
Five-year & $\begin{array}{c}\text { Total } \\
\text { Period }\end{array}$ & $\begin{array}{c}\text { Direct } \\
\text { (a) }\end{array}$ & $\begin{array}{c}\text { Tables } \\
\text { (c) }\end{array}$ & $\begin{array}{c}\text { Summaries } \\
\text { (d) }\end{array}$ \\
\hline $1882-1886$ & 57 & 47 & 44 & 42 \\
$1887-1891$ & 44 & 35 & 34 & 34 \\
$1892-1896$ & 47 & 44 & 38 & 37 \\
$1897-1901$ & 38 & 33 & 33 & 33 \\
$1902-1906$ & 23 & 19 & 21 & 21 \\
$1907-1911$ & 21 & 15 & 18 & 16 \\
$1912-1916$ & 22 & 16 & 17 & 17 \\
$1917-1921$ & 24 & 18 & 21 & 15 \\
$1922-1926$ & 28 & 25 & 26 & 27 \\
$1927-1931$ & 8 & 8 & $6 *$ & 19 \\
$1932-1936$ & 9 & 9 & 10 & 10 \\
$1937-1941$ & 14 & 13 & 12 & 12 \\
$1942-1946$ & 8 & 7 & 8 & 2 \\
$1947-1951$ & 8 & 7 & 6 & 6 \\
$1952-1956$ & 3 & 3 & 3 & 3 \\
$1957-1961$ & 1 & 0 & 0 & 0 \\
\hline
\end{tabular}

*misplaced neonates removed after detection.

\section{Determinants and Causes}

Loudon considers it essential to distinguish between the immediate or direct causes of maternal death on the one hand, and the causes of maternal mortality levels within the populations on the other. "It avoids confusion if the term 'causes' is used for the immediate causes of death and 'determinants' for the factors which determined whether the level of mortality in a population at a given time or place was low or high."4

Ogle's nosology provided seven causes against which deaths from pregnancy and childbirth were to be classified: 'puerperal fever', 'abortion and miscarriage', 'puerperal mania', 'puerperal convulsions', 'placenta praevia and flooding', 'phlegmasia alba dolens' and 'other accidents of pregnancy and childbirth'. It was into this framework and its subsequent modifications that the registrars had to fit the causes of the maternal deaths diagnosed by the doctors-and doctors when making their diagnoses did not always have easy classification in view. The early registrars - and at first there were 14 of them scattered about the Island-would have received little training in nosology, and some

${ }^{4}$ Ibid., p. 43. 


\section{G Pantin}

combined the post of registrar with another occupation: in the 1930s the station master at the village of Union Mills registered the deaths of inmates of the Lunatic Asylum and Home for the Poor, along with the deaths of others in the parish.

One consequence was that many more maternal deaths than necessary were placed in the nondescript category of 'Other accidents of pregnancy and childbirth': in 1883 the registrar of the little town of Ramsey (4,214 inhabitants) recorded that eight mothers had died in childbirth, among them one from puerperal fever and five from 'Other accidents .... He had failed to recognize three deaths registered as due to puerperal peritonitis for what they were.

Having extracted all the maternal deaths that could be found from the Registers of Death I thought it best to reclassify them and, before doing so, I modified Ogle's nosology as the basis for the classification of the causes of death in childbirth and adopted it in Appendix A. 'Puerperal mania' has been left out as a class, one of the two cases so diagnosed in the Registers, a woman who was in coma for 42 days, has been listed among the puerperal toxaemias and the other case has been placed among 'Other accidents of pregnancy and childbirth'. Deaths due to ectopic gestation are grouped with those due to pulmonary embolism as neither responds to the skills of midwives: embolism had to await the early mobilization of the mother and anticoagulants, and ectopic gestation the development of abdominal surgery and blood transfusion.

Two causes of death are introduced: 'debility' to cover the cases in which the subsidiary cause of death given by the doctor is debility, asthenia, exhaustion or anaemia without qualification, which suggests that the mother was malnourished or for some other reason in poor physical condition, and 'intervention' where there are grounds for believing that the interference of midwife or doctor caused the death. The new categories aided the salvaging of cases with a classifiable cause of death from among those which had been placed by the registrars against 'Other accidents of pregnancy and childbirth'. Of 57 so placed it was possible to reclassify 39 .

The nosology adopted has been set out on the first page of Appendix A. The information extracted from the Registers of Death is encoded in the tables in the Appendix and the keys to the codes will be found at the beginning. The maternal deaths recovered from the Registers of Death are numbered in each quinquennium starting from 1. The quinquennia are numbered from 1 to 16 . Thus to indicate a case in the text the number of the quinquennium is given before the number of the case, e.g., Q1/1.

\section{Corrections made for Changes in the Birth Rate}

When fewer babies are born there will be fewer opportunities for women to die in childbirth. The number of babies born annually on the Isle of Man fell steeply after the turn of the century owing to a fall in the fertility rate (the number of births per 1000 women aged 15 to 44 ). Between 1891 and 1931 the fertility rate on the Island more than halved. To correct for this, the ratios of mothers dying in childbirth per acceptable number of live births has to be calculated. Live births and not total births have to be used because stillbirths were not registered on the Isle of Man before October 1933. The number of live births to use as the denominator is a matter of choice; 100 would preserve a sense of proportion but only a larger figure dispels the need to express the maternal deaths/births 
Table 3

The number of births and of direct maternal deaths on the Isle of Man in each of the 16 quinquennia following 1881 , and the derived maternal mortality ratios per 10,000 births.

\begin{tabular}{lccc}
\hline $\begin{array}{l}\text { Five-year } \\
\text { Period }\end{array}$ & Births & $\begin{array}{c}\text { Direct Maternal } \\
\text { Deaths }\end{array}$ & $\begin{array}{c}\text { Maternal Mortality } \\
\text { Ratios }\end{array}$ \\
\hline $1882-1886$ & 7327 & 47 & 64 \\
$1887-1891$ & 7608 & 35 & 46 \\
$1892-1896$ & 7034 & 44 & 63 \\
$1897-1901$ & 6898 & 33 & 48 \\
$1902-1906$ & 5935 & 19 & 32 \\
$1907-1911$ & 5155 & 15 & 29 \\
$1912-1916$ & 4252 & 16 & 38 \\
$1917-1921$ & 3608 & 18 & 50 \\
$1922-1926$ & 3953 & 25 & 63 \\
$1927-1931$ & 3422 & 8 & 23 \\
$1932-1936$ & 3273 & 9 & 27 \\
$1937-1941$ & 3558 & 13 & 37 \\
$1942-1946$ & 4112 & 7 & 17 \\
$1947-1951$ & 4316 & 7 & 16 \\
$1952-1956$ & 3397 & 3 & 9 \\
$1957-1961$ & 3281 & 0 & 0 \\
\hline
\end{tabular}

ratio $(\mathrm{MD} / \mathrm{BR})$ as a fraction of a percentage. The $\mathrm{MD} / \mathrm{BR}$ in Table 3 has been calculated using 10,000 births as the denominator.

The graph in Figure 1 is derived from Table 3. It demonstrates the fluctuations in the MD/BR and the overall downwards trend, as well as the growing percentages of the total number of births which took place in the maternity home.

\section{Analysis}

"All chance, direction which thou canst not see". 5

Because of the small numbers of maternal deaths involved, the fluctuations of the maternal mortality rate on the Isle of Man shown in Figure 1 may have to be ascribed to chance. However an analysis of the data in Appendix A may indicate that there is either a cause or some determinants which affected the levels of maternal mortality.

In Table 4 the incidence of the causes of maternal deaths in each of the 16 quinquennia is shown. Puerperal sepsis, category $F$ in Table 4, caused many deaths before 1907, but, contrary to expectations, Figure 2 demonstrates that it did not play a significant role either in the fall of the MD/BR between 1882 and 1907-11 or in producing the subsequent spikes in the graph.

The causes of maternal deaths recorded in the Registers of Death and set out in Appendix A provide evidence of a steady improvement in the health of the mothers from

5 Alexander Pope, An essay on man. 


\section{G Pantin}

Figure 1: Graph A O__ $-O$ O shows the maternal mortality rates per 10,000 births on the Isle of Man in each of the 16 quinquennia following 1881. Graph B X-- -X-- -X shows the percentages of the births taking place in the Maternity Home.

70

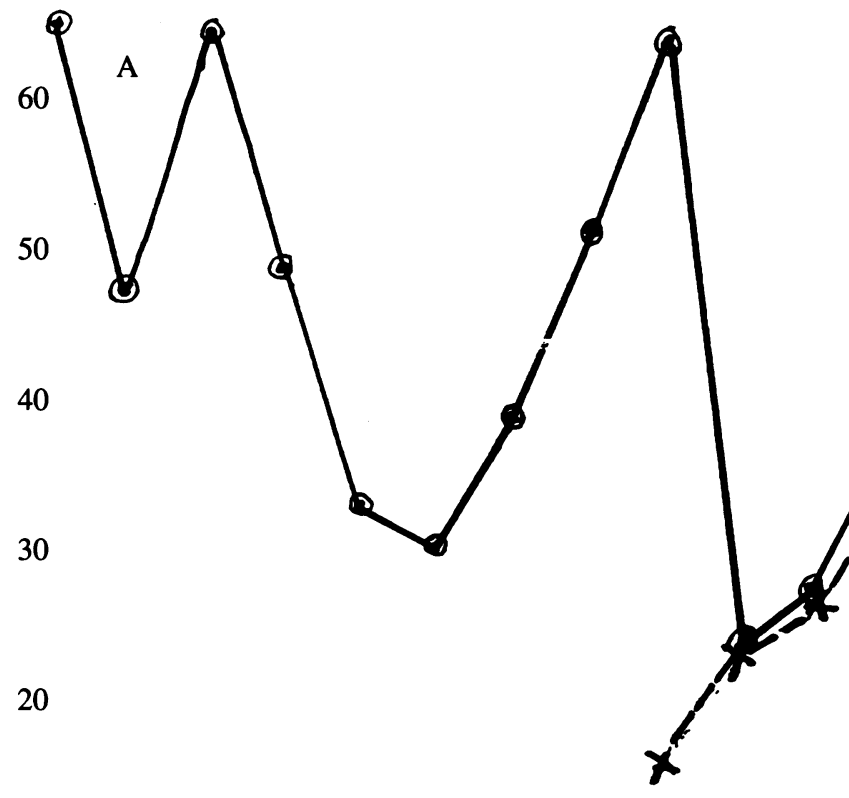

B

$100 \%$

10

0

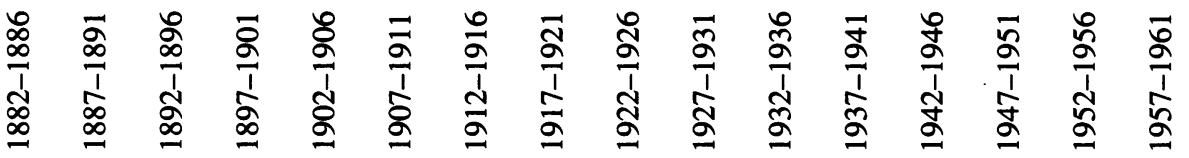

Quinquennia from 1 January 1882 to 31 December 1961

1882 onwards. First there was a reduction in the numbers dying from an associated disease as the years passed. In the last century women in the Isle of Man bore their children in a community carrying an appalling burden of sickness. The deaths discarded, so far as the statistics are concerned, as indirect deaths, show the presence of many diseases. During the first 40 years of the study there were 49 maternal deaths due to associated diseases (18 per cent of the total) and during the second 40 years the number was down to 7, or 9 per cent of all maternal deaths. Then, in succeeding decades, fewer deaths from childbirth are recorded in which debility, asthenia, exhaustion or anaemia is given as the only subsidiary cause of death. Because these subsidiary causes of death have connotations of malnutrition or of occult disease, such as tuberculosis, the fall in their numbers implies the improved well-being of the mothers. Deaths from childbirth in which one of these and no 
Table 4

The number of births and of direct maternal deaths on the Isle of Man in each of the 16 quinquennia following 1881 coded as in Appendix A. B=bleeding, C=toxaemia, D=debility, $\mathrm{E}=$ ectopic or emboli, $\mathrm{F}=$ sepsis, $\mathrm{I}=$ intervention, $\mathrm{O}=$ other accidents of pregnancy and childbirth.

\begin{tabular}{|c|c|c|c|c|c|c|c|c|}
\hline \multirow{2}{*}{$\begin{array}{l}\text { Five-year } \\
\text { Period }\end{array}$} & \multirow{2}{*}{$\begin{array}{c}\text { Births } \\
7327\end{array}$} & \multicolumn{7}{|c|}{ Direct Maternal Deaths from: } \\
\hline & & 8 & 6 & 3 & 1 & 19 & 1 & 9 \\
\hline $1887-1891$ & 7608 & 11 & 11 & 2 & 0 & 8 & 0 & 3 \\
\hline $1892-1896$ & 7034 & 4 & 9 & 6 & 3 & 16 & 1 & 5 \\
\hline $1897-1901$ & 6898 & 7 & 5 & 2 & 5 & 12 & 0 & 2 \\
\hline $1902-1906$ & 5935 & 3 & 3 & 0 & 0 & 11 & 0 & 2 \\
\hline $1907-1911$ & 5155 & 0 & 6 & 0 & 2 & 4 & 0 & 3 \\
\hline $1912-1916$ & 4252 & 2 & 5 & 1 & 2 & 4 & 0 & 2 \\
\hline $1917-1921$ & 3608 & 1 & 4 & 2 & 2 & 7 & 0 & 2 \\
\hline $1922-1926$ & 3953 & 5 & 7 & 0 & 3 & 3 & 4 & 3 \\
\hline $1927-1931$ & 3422 & 1 & 2 & 1 & 0 & 2 & 1 & 1 \\
\hline $1932-1936$ & 3273 & 4 & 2 & 0 & 0 & 3 & 0 & 0 \\
\hline $1937-1941$ & 3558 & 4 & 5 & 0 & 1 & 1 & 0 & 2 \\
\hline 1942-1946 & 4112 & 2 & 2 & 0 & 1 & 2 & 0 & 0 \\
\hline 1947-1951 & 4316 & 2 & 1 & 0 & 3 & 0 & 1 & 0 \\
\hline $1952-1956$ & 3397 & 1 & 2 & 0 & 0 & 0 & 0 & 0 \\
\hline 1957-1961 & 3281 & 0 & 0 & 0 & 0 & 0 & 0 & 0 \\
\hline
\end{tabular}

Table 5

\begin{tabular}{lccc}
\hline Period & Births & $\begin{array}{c}\text { Number of } \\
\text { D category } \\
\text { Maternal Deaths }\end{array}$ & $\begin{array}{c}\text { The MD/BR of } \\
\text { D category } \\
\text { Maternal Deaths }\end{array}$ \\
\hline $1882-1901$ & 28,867 & 13 & 4.5 \\
$1902-1921$ & 18,950 & 3 & 1.6 \\
$1922-1941$ & 14,206 & 1 & 0.7 \\
$1942-1951$ & 14,106 & 0 & 0.0 \\
\hline
\end{tabular}

other subsidiary cause of death is given have been placed in category $D$ in Table 4. Table 5 gives an analysis of this category.

The levels of infant mortality and of deaths from tuberculosis are often regarded as good indicators of the health of a community and on the Isle of Man the MD/BR fell in unison with the levels of both these indicators up to 1911 (Table 6 and Figure 3). This also suggests that the downwards trend in the MD/BR until this date is reached is due to an improvement in the mothers' health. (Please note that in Figure 3 the numbers of deaths of infants under one year of age have been divided by two so that the graphs can be more congruent.)

A survey of Appendix A reveals little evidence of intervention during the years from 1882 to 1911 when the MD/BR was falling: intervention appears to have played a part in 


\section{G Pantin}

Figure 2: Graph A O - - - O - - - O shows the direct maternal deaths per 10,000 births on the Isle of Man in each of the 16 quinquennia after 1881. Graph B $\longrightarrow$ shows the direct maternal deaths less the deaths due to puerperal sepsis per 10,000 births (abortions excluded).

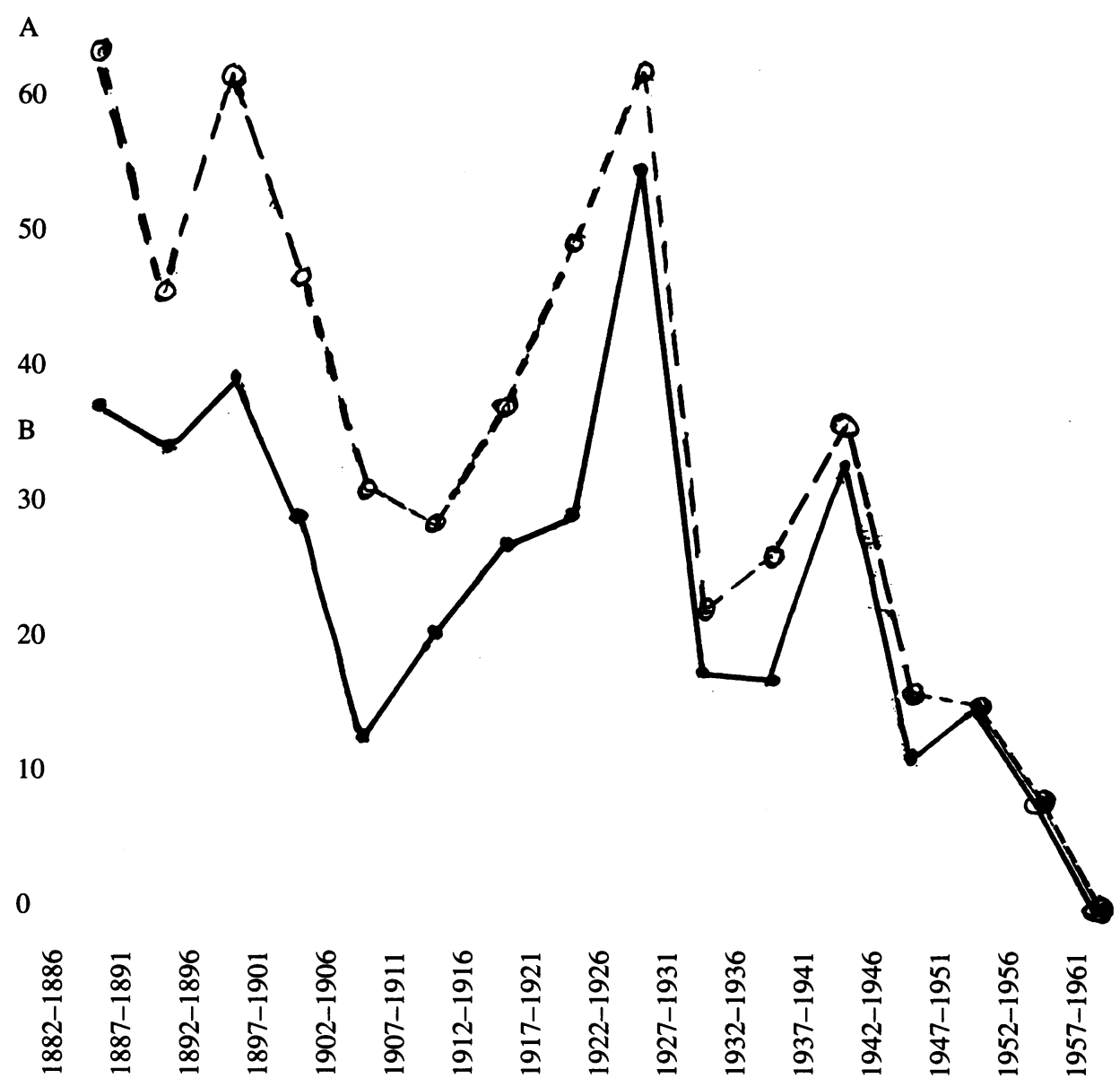

Quinquennia from 1 January 1882 to 31 December 1961

only three deaths among the 230 maternal deaths recorded between 1881 and 1912 . In $\mathrm{Q} 2 / 24$ induction is mentioned in the cause of death. In Q1/48 and Q3/42 the womb had become inverted due, it may be presumed, to the attendant pulling on the cord when trying to deliver an adherent placenta, but the fact that the mother had died before the womb had been replaced suggests a lack of readiness to intervene manually.

As the MD/BR rose after 1911 the evidence to be found in Appendix A suggests that intervention was taking place more frequently and that doctors were involved. Before 191297 per cent of the maternal deaths are registered as occurring at a private address, presumably the mother's abode. In 1914 a Caesarian section was performed in Noble's Hospital (Q7/18). The mother died from septicaemia. Between 1911 and 192731 per cent of the deaths took place in Noble's Hospital and other institutions. 
Table 6

The number of births and of infant deaths under one year of age, the derived infant mortality ratios per 1000 births, the maternal mortality ratios per 10,000 births and the deaths from tuberculosis per 5000 living on the Isle of Man in each of the 16 quinquennia following 1881.

\begin{tabular}{|c|c|c|c|c|c|}
\hline \multirow[b]{2}{*}{$\begin{array}{l}\text { Five-year } \\
\text { Period }\end{array}$} & \multirow[b]{2}{*}{ Births } & \multicolumn{2}{|c|}{ Deaths age $<1$ Year } & \multirow{2}{*}{$\begin{array}{c}\text { Maternal } \\
\text { mortality } \\
\text { per } 10,000 \\
\text { live births }\end{array}$} & \multirow{2}{*}{$\begin{array}{c}\text { Deaths from } \\
\text { tuberculosis } \\
\text { per } 5000 \\
\text { living }\end{array}$} \\
\hline & & Actual & $\begin{array}{l}\text { per } 1000 \\
\text { births }\end{array}$ & & \\
\hline $1882-1886$ & 7327 & 825 & 113 & 64 & 102 \\
\hline $1887-1891$ & 7608 & 964 & 127 & 46 & 82 \\
\hline $1892-1896$ & 7034 & 907 & 129 & 63 & 78 \\
\hline $1897-1901$ & 6898 & 909 & 132 & 48 & 73 \\
\hline $1902-1906$ & 5935 & 667 & 112 & 32 & 63 \\
\hline $1907-1911$ & 5155 & 546 & 106 & 29 & 59 \\
\hline $1912-1916$ & 4252 & 402 & 95 & 38 & $51 *$ \\
\hline $1917-1921$ & 3608 & 305 & 85 & 50 & $51^{*}$ \\
\hline $1922-1926$ & 3953 & 293 & 74 & 63 & 41 \\
\hline $1927-1931$ & 3422 & 191 & 56 & 23 & 30 \\
\hline $1932-1936$ & 3273 & 169 & 52 & 27 & 26 \\
\hline $1937-1941$ & 3558 & 197 & 55 & 37 & 18 \\
\hline $1942-1946$ & 4112 & 146 & 36 & 17 & 13 \\
\hline $1947-1951$ & 4316 & 138 & 32 & 16 & 9 \\
\hline $1952-1956$ & 3397 & 91 & 27 & 9 & 5 \\
\hline $1957-1961$ & 3281 & 70 & 21 & 0 & 3 \\
\hline
\end{tabular}

*includes deaths from tuberculosis among prisoners of war.

Convincing evidence of intervention is provided by a cluster of cases recorded during the 9th quinquennium, 1922-1926; cases 22, 23, 24 and 25. Two of the mothers died following the rupture of the uterus. No death from rupture of the uterus was recorded during the previous eight quinquennia, and in Q9/22 the death certificate stated that the rupture was "instrumental" and that it was followed by a hysterectomy. In the third case the death was again cited as "instrumental", and the fourth was an anaesthetic death.

These four cases, which contribute 10 to the high MD/BR of 63 that was recorded between 1 January 1922 and the end of 1926, can only have been caused by the intervention of doctors. This evidence of the greater involvement of doctors puts them under suspicion of being the cause of the increased maternal mortality due to bleeding and toxaemia during this period. "Differences in maternal mortality can seldom be pinned down to a single cause of death. If maternal mortality was high (or low) it was high (or low) for all causes of maternal mortality."6

It thus appears that until 1914 the approach to childbirth on the Isle of Man was conservative. During this period the MD/BR fell. Thereafter doctors began to practise intervention and they thereby increased maternal mortality until 1927 . Then a rapid fall occurred due, presumably, to the opening of the Jane Crookall Maternity Home.

\footnotetext{
${ }^{6}$ Loudon, op. cit., note 1 above, p. 44.
} 


\section{G Pantin}

Table 7

The death rates per 1000 living on the Isle of Man, and the number of deaths of persons under 15 years of age and of those who died after surviving until 65 years of age expressed as percentages of the total deaths in the years stated.

\begin{tabular}{lccc}
\hline Year & $\begin{array}{c}\text { Death rate } \\
\text { per } 1000\end{array}$ & $\begin{array}{c}\% \text { of total deaths of those who died } \\
\text { under } 15 \text { years of age and over 65 years }\end{array}$ \\
1880 & 21.9 & 41 & 25 \\
1890 & 20.9 & 33 & 30 \\
1900 & 20.5 & 28 & 27 \\
1910 & 15.3 & 22 & 41 \\
1920 & 14.9 & 17 & 42 \\
1930 & 14.4 & 12 & 53 \\
1940 & 17.3 & 5 & 60 \\
1950 & 14.9 & 6 & 75 \\
1960 & 14.3 & 4 & 76 \\
\hline
\end{tabular}

Deaths among service personnel undergoing training or lost at sea and whose bodies were washed up on the beach contributed to the death rate on the Island in 1940.

\section{Economic, Social and Medical Background}

\section{The Manx Economy}

Conditions on the Isle of Man in 1878 were deplorable. Just how bad they were was disclosed by a commission which began to sit in October of that year. ${ }^{7}$ The Commission found a community of some 50,000, half urban, half rural, without a compulsory poor rate, so that the indigent and sick, many of them malnourished and alcoholic, had to depend on private charity for relief; an island where there was one small hospital in a dwelling adapted for the purpose in 1850 and capable of accommodating comfortably only 14 patients (although during the smallpox epidemic of the previous winter as many as 23 patients had been crowded into it, there being no fever hospital); an island where the only nurse who had had any formal training was the hospital matron; and where, as Dr Ring reported to the Commission: "I am afraid that many deaths have occurred in Douglas from want of a lying-in hospital, and especially from the want of proper food. This is what I call 'starvation' - the blood is starved. I have known cases of women who have been confined, dying from want of accommodation and proper food for them at such a time." (Dr Ring's evidence must not be taken to imply that the women were worse off than the men.)

In 1878 the inhabitants of the Isle of Man were beginning to recover from a hundred years of impoverishment: between 1765 and 1866 the United Kingdom Parliament had retained the duty paid on goods entering the Island. During this period "the Island was, in fact, without an insular revenue, without an annual budget, and without resources for development". 8

\footnotetext{
${ }^{7}$ Medical aid and poor relief commission (Isle of Man), Douglas, I.O.M., Printed (by authority) by James Brown \& Son, 9 Athol Street, 1879.
}

\footnotetext{
${ }^{8} \mathrm{G}$ E Moore and J B Bolton, Constitution of the Isle of Man and financial aspects of the Isle of Man Government, Douglas, I.O.M., Printing Committee of Tynwald, 1974, p. 4.
} 
Figure 3: Direct maternal deaths per 10,000 births shown in Graph A $\longrightarrow \longrightarrow \longrightarrow$ are compared with the infant mortality under one year of age per 500 births in Graph B X-X $-\mathrm{X}$, and with the number of deaths from tuberculosis per 5000 living in Graph $\mathrm{C} \mathrm{O}$ Man in each of the 16 quinquennia following 1881.

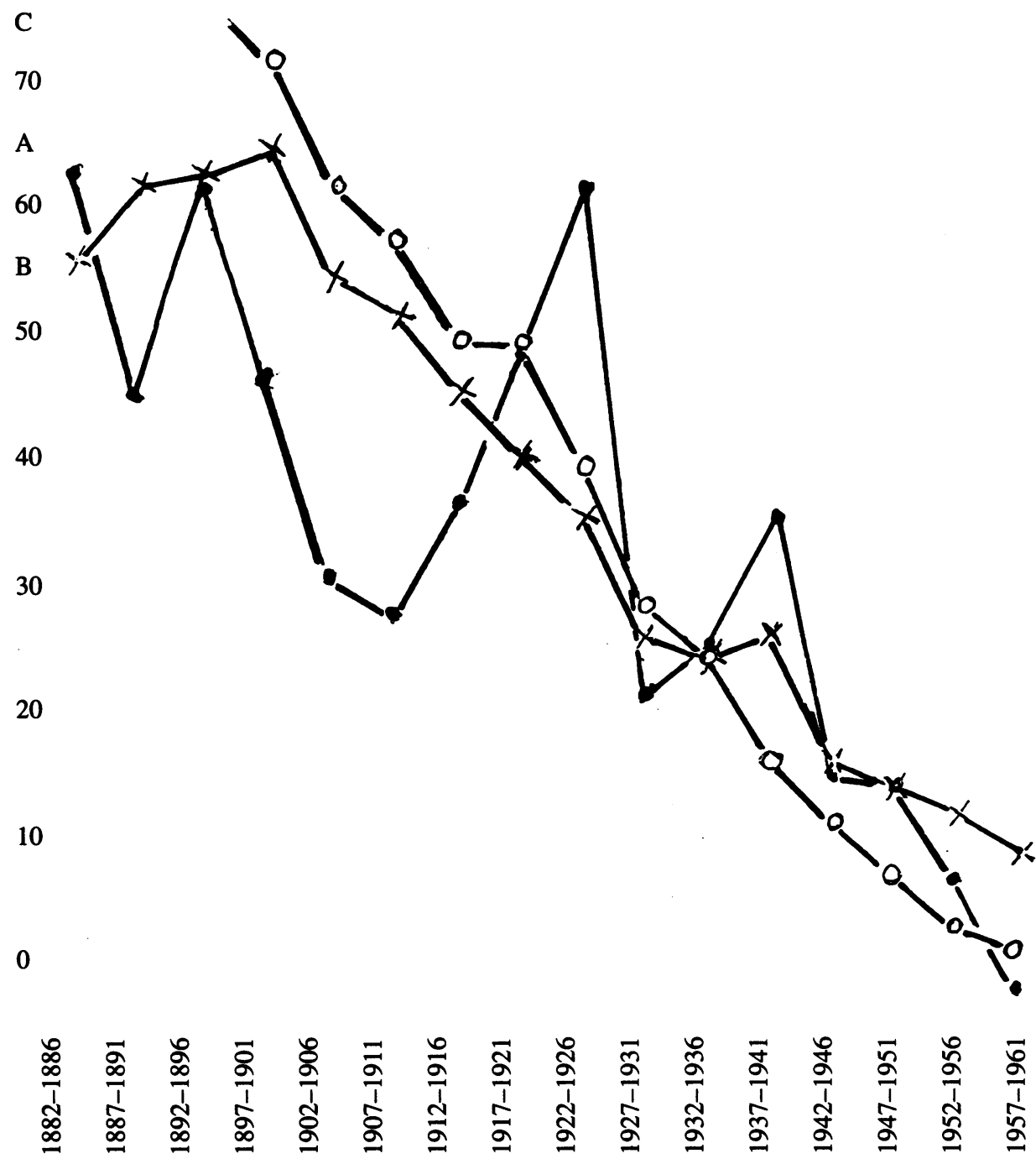

Quinquennia from 1 January 1882 to 31 December 1961

In 1866 the Lieutenant Governor persuaded the UK government to adopt an arrangement whereby the Island was allowed to keep most of the Customs' revenue. Thereafter began the capital expenditure needed to build up the tourist trade on which the prosperity of the Island so largely depended until well into the second half of the twentieth century. In 1892 the number of passenger arrivals recorded from the 1 May to 30 


\section{G Pantin}

September (chiefly visitors) was 274,096 ; by 1913 the number had risen to $634,512 .{ }^{9}$. The two world wars and the depression between them caused relatively minor setbacks. If the state of affairs disclosed by the 1878 Commission is compared with 1961 standards and Table 7 consulted, only two conclusions can be reached: the living conditions of the Manx and their health improved between 1878 and 1961.

\section{The Quality of Obstetric Care, 1882-1926}

Registration by the General Medical Council was not obligatory for a doctor wishing to practise on the Isle of Man until 1899. Of the 57 maternal deaths recorded in the Registers of Death during the first quinquennium following 188110 were registered by "some person present at the death, or in attendance during the last illness" and not certified by a doctor. This practice fell into disuse several years before the end of the nineteenth century. During this time many women could not afford to pay a doctor to attend them and, without motor cars, the number of parturient women doctors could reach was limited. Doctors, however, were called in when catastrophe threatened, for it was they who signed most of the death certificates.

Thus the majority of deliveries were at first in the hands of untrained midwives and handywomen living near by. This practice would have been all the more likely because many of the Islanders spoke only Manx and when ill they tended to turn to their own folkdoctors. Dr Clague, himself a native Manx speaker, called these doctors 'charmers' because they relied heavily on the recitation of charms to effect their cures. "It [the charm] was a secret [silent] prayer to God the Father, the Son, and the Holy Spirit, or to the angels, or saints, to heal the man. They believed that God would do it if it was His wish, and it was indeed faith-healing."10

The numbers of trained nurses and of midwives on the Island grew only slowly. In 1884 it was arranged that a nurse from the Hospital should visit patients in their homes in Douglas. In 1892 it was stipulated that the nurse should be "skilled". By this time the patients had been moved into a hospital of 42 beds built by a prominent businessman, $\mathrm{Mr}$ Noble, as a gift to the people of Douglas. The nursing staff of Noble's Hospital consisted of a matron, five nurses and four probationers. ${ }^{11}$ At the beginning of this century voluntary associations were formed to solicit funds and employ trained nurses to work among the poor. In 1906 a midwife was appointed to work in Douglas. In 1909, when the midwife's salary was raised to $£ 90$ a year, the Douglas Maternity Nurse delivered 56 women and made 900 visits.

Although there were Manx bone-setters, the Islanders were averse to anything amounting to an operative procedure. In the year ending 30 June 1896 no operation more severe than a tracheotomy was performed at the Hospital and the only major operations performed before then were the amputation of shattered limbs. Dr Clague recounts how a man was brought to him by a folk-doctor who had failed to stem the flow of blood from

\footnotetext{
${ }^{9}$ The official Isle of Man year book 1995, Douglas, I.O.M., Mannin Media Group, 1995, pp. 202-3.
}

$10 \mathrm{~J}$ Clague, Manx reminiscences; Cooinaghtyn

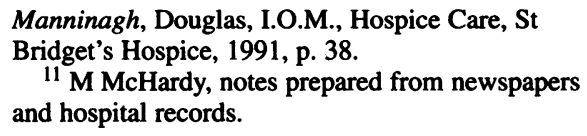
and hospital records. 


\section{Maternal Mortality and Midwifery on the Isle of Man}

a wound by the repeated recitation of a charm, reputedly effective on such an occasion. Dr Clague asked the charmer to repeat the charm and he did so, several times, but the bleeding did not stop. "A bandage properly put on stopped it at once." This example of the disinclination of the Manx to make use of elementary surgical procedures, which almost certainly included the use of forceps during childbirth, is supported by the advice given by Dr Clague, shortly before his death in 1908, to the house surgeon at Noble's Hospital: "Don't be too ready to operate, ask the relatives, if they say cut, cut! if they say' don't cut, don't cut!" Manx beliefs and practices during these years were consistent with the belief, derived from the analysis of Appendix A, that on the Island obstetrical practice was conservative in nature.

From 1912 to 1926, as the analysis of the data in Appendix A shows, doctors were taking over more midwifery practice. One reason for this may have been the greater mobility doctors acquired through the motor car. It was also a period during which the Manx lost their prejudices against surgery. Among the reasons for this was the appointment to the Honorary Staff of Noble's Hospital of a competent surgeon, C S Pantin MD, FRCS, trained in aseptic measures, and the experiences many of the Manx would have had during the First World War; between 1914 and 19198261 men and women joined the armed forces. This number included 82.3 per cent of the Island's males of military age. ${ }^{12}$ Another factor may have been the effect of the introduction in 1872 of compulsory attendance at schools, where the lessons were in English; by 1901 only 4598 Manx speakers remained and their numbers were dwindling fast. Lastly, growing prosperity may have enabled more families to pay doctors' fees. These changes would have allowed doctors to displace the midwife as the pregnant woman's first choice as the attendant at her birth.

At the same time, steps were being taken to raise the competence of midwives on the Isle of Man so that more and more Manx handywomen would be displaced. In 1922 an Act of Tynwald required midwives to register for the first time. ${ }^{13}$ The Act did not lay down any standard of professional training but it empowered the Local Government Board to "make regulations with reference to the practice of midwifery, and, in particular, as to the cleanliness, character, and conduct of midwives", and to strike any midwife off the list if deemed unsuitable. Under the Nurses and Midwives Act of 1947 it became illegal for any nurse to practise as a midwife on the Isle of Man who had not been certified as qualified to do so by one of the Central Midwives Boards.

From 1912 onwards the management of childbirth passed into the hands of doctors and certified midwives, acting either singly or together. By $1927 \mathrm{few}$, if any, untrained midwives were active. Why then did maternal mortality rise during this period?

Doctors faced difficulties when called upon to help during childbirth in private dwellings, as these were often small and ill-supplied with amenities. Mr J Kneen of Ballaugh in 1950 when aged 97 recounted how "The houses were mostly small, and even the farmhouses were nothing in comparison with what they are today. It was nothing unusual for a man, his wife, and a large family of children to live in two rooms".

\footnotetext{
12 M West, Island at war, Ballaragh, I.O.M., Western Books, 1986, Introduction.
}

\footnotetext{
13 The Local Government Amendment Act 1922, sections 51-54, Statutes of the Isle of Man, 1921-1924, vol. 11 .
} 


\section{G Pantin}

When an abortive attempt was being made in 1924 to establish a maternity ward at Noble's Hospital, Dr C S Pantin reported:

Amongst the very poor in Douglas, and the Island generally, the conditions of life are so bad that one is frequently astonished that a woman can survive among so great dangers. I have been at confinements when there was no bowl available to wash the hands, and the woman lay on a filthy mattress on the floor. It is quite a common thing for the husband and elder children to have to sleep with the woman, after her confinement, because there is no other bed available for them. ${ }^{14}$

Conditions in Manx homes were not conducive to successful intervention and this may have been the chief reason why maternal mortality rose from 1914 until a maternity home was opened.

\section{Jane Crookall Maternity Home}

There was nothing pretentious about the eleven-bedded maternity home which opened in Douglas on 6 May 1927. It was in a boarding house which had been bought and modified for the purpose by the Mayor of Douglas, Alderman A B Crookall. The Home was to be a memorial for his wife Jane, and a home where the poorer people could enjoy a fortnight's rest with good food after being delivered by competent midwives. ${ }^{15}$ The relevant features were a room for antenatal examinations on the ground floor, a wellequipped labour room on the first floor and a resident nursing staff. This, consisting at first of a matron and two midwives, had by the end of the decade been increased by two more midwives.

All the family doctors on the Isle of Man had access but there was a Honorary Surgeon in charge, Dr Dorothy Pantin. She was the first woman to practise medicine on the Isle of Man and she had a particular interest in obstetrics. During the first decade about half the mothers admitted to the Home were delivered by the midwives unaided. The Honorary Surgeon gave help with 80 per cent of the rest and half a dozen Douglas doctors helped with their private patients. Much of the help given by the doctors was of a minor nature, administering gas and oxygen anaesthesia for instance, or suturing perineal tears.

Following the opening of the Maternity Home the MD/BR on the Isle of Man halved: having been 63 during the five years 1922 to 1926 it fell to 23 during the next quinquennium, although 85 per cent of the mothers were still being delivered in their own homes. The MD/BR was now lower than it had been in the 6th quinquennium, 1907 to 1911. It was as if any ill-effects the interventions of doctors might have had had been eliminated. This could have been due to doctors sending their complicated deliveries into the Maternity Home and the staff there being more successful in dealing with the women's problems. The Maternity Home did, in fact, admit emergencies. In 1924 a motor ambulance had been bought for Noble's Hospital and when the Home opened family doctors could send their problem cases from the most distant parts of the Island. A rigorous study of the registers kept by the midwives on the staff of the Home revealed that

\footnotetext{
${ }^{14}$ Debates in the Manx Legislature, $\frac{\mathrm{D}}{152 / 1}, \mathrm{p}, 797$.

${ }^{15} \mathrm{C}$ G Pantin, The story of the Jane Crookall
}

Maternity Home, Douglas, I.O.M., Hospice Care, St Bridget's Hospice, 1992, p. 13. 
of the 4778 mothers admitted during the two decades between 1926 and 1947, 157 were described in the registers as being "emergencies".

The presence of the peak in the MD/BR in the 12th quinquennium gives further support to the belief that by taking in the complicated cases, and thus relieving the doctors of the need to struggle with the deliveries in the mothers' abodes, the Home saved lives. The Honorary Surgeon told the Management Committee of the Maternity Home on 28 August 1937 that the number of women being admitted to the Home created such a demand for beds that some patients were in danger of being sent out before the 14 days' rest period had elapsed: the Home was suitable for only 156 patients during a year. During 1937 there were 205 admissions, in 1938 213, and in the first six months of 1939 117. In July 1939 the Home reopened in a purpose-built Jane Crookall Maternity Home, which was much larger. Thus in the first half of the 12th quinquennium the old Home was overcrowded and the staff may well have been unable to admit some emergencies. The proportion admitted as emergencies did indeed fall (see Appendix B) and the possibility is supported by the data given in Appendix A for the 12th quinquennium. Here the year or, in 1939, the day and month when each mother died is stated. During the first 30 months of the quinquennium six mothers (Q12/2,/3,/4,/7,/8,/13) died outside the Home and only one (Q12/6) inside. The doctors may have had to manage their difficult cases as best they could in the mothers' homes as they did before 1927.

A search for any cause for the fall in the MD/BR after 1926 other than the facilities offered by the Maternity Home proved fruitless. In 1928 extracts of ergot began to be given orally in the Home and the first Caesarian section since 1914 was performed in Noble's Hospital in the same year. The oral preparations of ergot were probably inert: data in Appendix B does not show any effect on postpartum bleeding until injectable ergometrine was introduced. Both emergency Caesarian sections and blood transfusion came into use much later. The efficacy of the care provided in the Home was undoubtedly greater than that which could be given by the doctors when delivering a mother in her abode: of the 4778 mothers admitted during the two decades ending 31 December 1946 the only ones who died in the Home were 10 sent in, mostly in extremis, as emergencies (see Appendix B). If these 10 are excluded, the MD/BR of the mothers delivered in the Home during the two decades is zero. For the balance of the mothers, some 9750, who gave birth during the period in their abodes, plus the 157 admitted to the Home as emergencies, the MD/BR is 37 .

The procedures practised in the Maternity Home during the decade which followed its opening can be described as pre-Caesarian: podalic version, at times followed by "plugging with the half-breech" to control bleeding in placenta praevia, perforation of the head and extraction, and the use of forceps. Using these methods in the Home, doctors achieved a MD/BR of 23. It is surprising that midwives, handywomen and doctors who did not practise intervention were able to achieve a MD/BR of 29 when it was found to be advisable to intervene quite frequently in the Maternity Home to achieve a MD/BR of 23 (Appendix B). For this there seem to be two explanations: one, that in the Maternity Home much of the interference was in the interests of making birth easier rather than in saving life, and two, that nature when left to itself can overcome many difficulties which, to doctors watching women in labour, seem insuperable. This would mean that before there was intervention some labours were protracted, and of course we know they were: "When labours were slow, they were ready-possibly too ready-to wait for nature to take its 


\title{
C G Pantin
}

course". ${ }^{16}$ Rudyard Kipling's mother was in labour for six days before he was born but, when she returned from India with the hope that intervention in England would lead to a less stressful second birth, delivery by forceps was harrowing and injurious to the infant. ${ }^{17}$

By the time that the Health Service was introduced in 1948 all of the 23 general practitioners used the Home where, by then, half the deliveries on the Island were being performed.

\section{Effect of the Health Service}

Under the regulations introduced in 1948, antenatal, intrapartum and postpartum care were treated separately. A general practitioner could undertake to provide antenatal and postpartum care and delegate the responsibility of the delivery to another doctor. On the Isle of Man this meant delivery in the Maternity Home. No consultant obstetrician and gynaecologist was to reside on the Island until 1969. During 1968, five of the twenty-four family doctors provided antenatal and postpartum care only, leaving nineteen to undertake "care during the confinement" for their own patients and those the five had delegated. The doctors were not expected to deliver the mothers whose intrapartum care they undertook; midwives usually delivered them. Doctors were expected to be present at the birth in case the midwives asked for assistance. The midwives' register for the year credits the midwives with delivering 561 of the 621 babies, and doctors with delivering 60. Forceps were used on 33 of the cases the doctors delivered. Usually a doctor would apply the forceps on his own cases; only one, besides the five doctors who delegated, relied on his partner. In addition 34 babies were delivered by Caesarian section. Other procedures recorded during the year were:

Inductions (using buccal pitocin with or without ARM) 25

$\begin{array}{lr}\text { Episiotomies } & 77\end{array}$

Repairs of perineum $\quad 184$

Manual removal of adherent placenta 10

During the fifteen years from 1957 to 1971 , there were no maternal deaths in the Maternity Home, where 9760 mothers were delivered. Specific remedies had become available for some of the causes of maternal death. There were no more swift septicaemic deaths characteristic of infection with beta-haemolytic streptococci after the introduction of the sulphonamides in 1936. Those mothers who died of sepsis subsequently had an illness lasting many weeks, Q12/12, Q13/7 and 8, and these ceased after penicillin became available. Banked blood and ergometrine reduced the risk of death from bleeding. Three mothers died outside the Home between 1956 and 1972; two from pulmonary emboli and one from the rupture of a scar left by a previous Caesarian section. During this period the MD/BR on the Island was 2.9.

\section{Summary}

The living conditions and the health of Manx mothers continued to improve from 1881 to 1961. Against this background they were at first delivered conservatively and mostly

\footnotetext{
${ }^{16}$ Loudon, op. cit., note 1 above, p. 183.
}

\author{
${ }^{17}$ G Daly, Pre-Raphaelites in love, London, \\ Fontana, 1990, pp. 286/7.
}




\section{Maternal Mortality and Midwifery on the Isle of Man}

by midwives. During this conservative phase the proportion of mothers surviving childbirth increased as their health improved: by the quinquennium 1907-1911 the maternal mortality rate on the Island was half what it had been twenty years earlier.

Between 1912 and 1927 maternal mortality rose and during the quinquennium 1922-1926 the MD/BR was again at the level it had been thirty years before. Some of the maternal deaths during the quinquennium were among women who were subjected to intervention during childbirth by doctors in the unfavourable surroundings of their homes; conditions more suited to delivery by the conservative methods of kindly and patient handywomen.

Following the opening of a small maternity home on 6 May 1927 the family doctors began to send their difficult deliveries into the Home where they were looked after by skilled staff and delivered in a well-equipped labour room. Throughout the subsequent decade the MD/BR remained at a level below that in 1907-1911.

\section{Reconciliation with Loudon}

Loudon was puzzled by two of his findings. The first was the plateau of maternal mortality that occurred in nearly every country in the western world during the years between 1850 and 1936. The plateau as it appears in England and Wales is shown in Figure 4. This is a reproduction of Fig 1.4 from Death in childbirth, which was drawn on semi-log graph paper and, in order to make comparisons easy, the fluctuating course of maternal mortality on the Isle of Man shown in Figure 1 has been redrawn on the same scale on top of the graph for England and Wales.

Loudon was also puzzled by the paucity of evidence showing that an improvement in the health of the mothers reduced maternal mortality. Although the standard of living rose throughout the British Isles after 1880 and although he regarded the health of the mothers as being one of the two independent variables which determined the level of the maternal mortality rate, Loudon could cite no instances where its effect could be seen. The other determinant Loudon recognized was the quality of the obstetric care which the mothers received; this he linked with the type of birth-attendant. He advised that we should look for situations in which one of these two determinants did not change while the other did and see what happened. ${ }^{18}$

The summary above shows that such situations occurred on the Isle of Man because the Manx would not accept intervention in childbirth until after the first decade of the present century: on the Island the MD/BR fell up to 1911 while the management of childbirth did not change and the health of the mothers improved. In England and Wales the fall to 1910 is almost indiscernable (Figure 4), although it is enough to have caused Loudon to divide the period before 1936 into two phases; one leading up to 1910 and a second, during which the MD/BR recovered its previous slight fall, lasting until 1936.

This difference between the course of the MD/BR on the Isle of Man and in the rest of the British Isles may well be explained by the fact that family doctors in the United Kingdom had begun to intervene in childbirth before $1880 .{ }^{19}$ Thus in England and Wales the quality of obstetric care may have been changing throughout the whole period under review and not just since 1910 as on the Isle of Man. Loudon quotes several sources indicating that the intervention-prone family doctors caused a higher maternal death rate

\footnotetext{
${ }^{18}$ Loudon, op. cit., note 1 above, p. 48.

${ }^{19}$ Ibid., pp. 183-4.
} 


\section{G Pantin}

Figure 4: Maternal mortality rates (MMR) (five-year averages and logarithmic scale) on the Isle of Man, 1882-1961 - . . . . - in England and Wales, 1850-1980

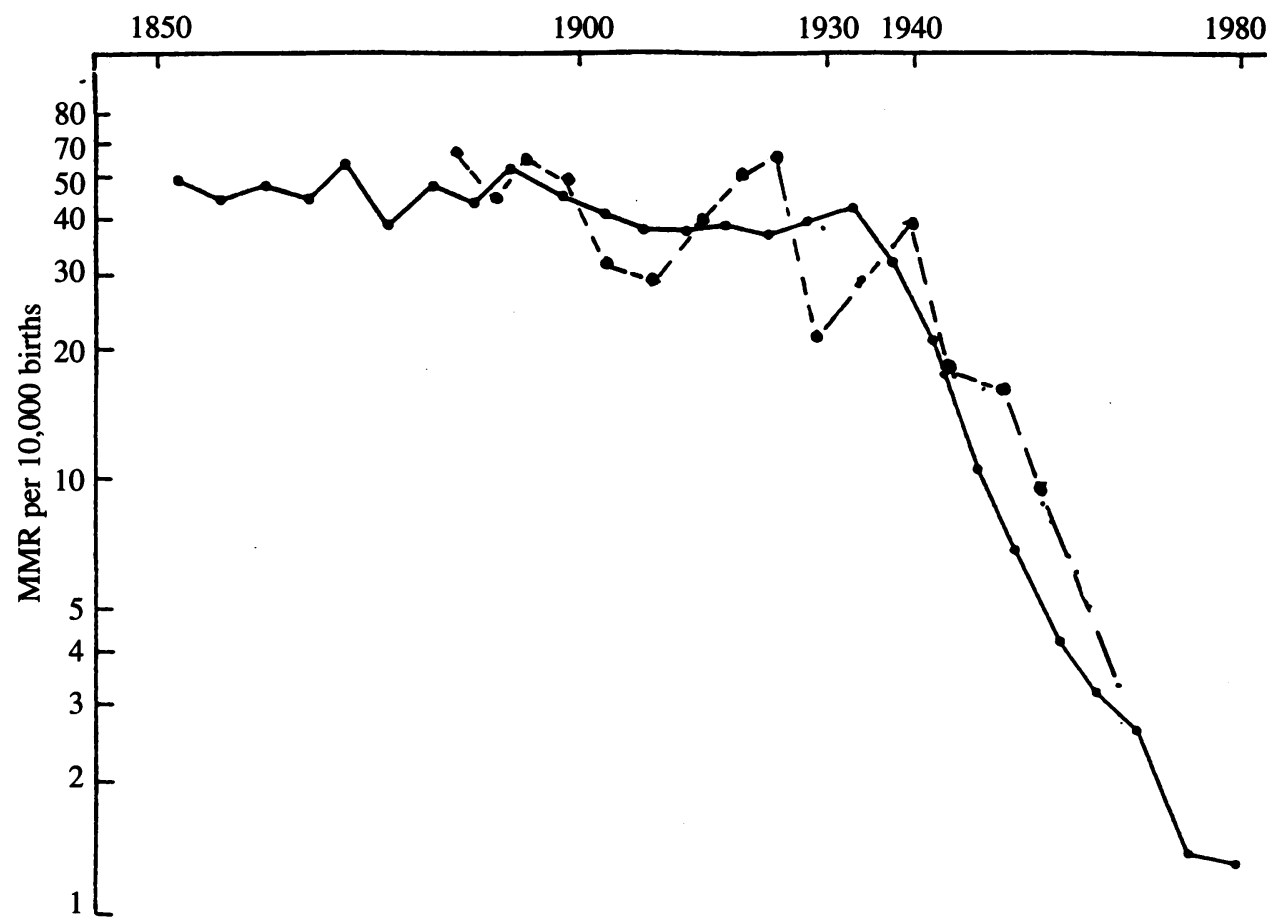

Source: Registrar General for England and Wales, Decennial supplements.

than did the midwives. ${ }^{20} \mathrm{He}$ also notes that the doctors were busily expanding their practices at the expense of the midwives between 1880 and $1936 .{ }^{21}$ These two factors combined would have the effect of progressively pushing the MD/BR up and so nullifying the benign effects of the better health of the mothers. The resulting plateau may be an example of a Simpson's paradox (defined as an example of confounding in which the third factor reverses the effect first observed). ${ }^{22}$ Following a similar line of thought it might be surmised that the benign effect of the mothers' improving health predominated up to 1910 , and thus the level of the plateau of maternal mortality in the United Kingdom fell slightly, and that after 1910 the doctors' increased radius of activity, resulting from their use of the motor car, caused the MD/BR to rise.

\section{Conclusions}

Although the profound fall in the maternal mortality rates after 1936 was achieved by attacking the specific causes of death in childbirth (sepsis by antibiotics, exsanguination

${ }^{20}$ Ibid., p. 244. See also, A Topping, 'Maternal mortality and public opinion', Public Health, 1936, 49: 342-9, and W H F Oxley, M H Phillips, J Young, 'Maternal mortality in Rochdale', Brit. med. J., 1935, i: 304-7.

\footnotetext{
${ }^{21}$ Loudon, op. cit., note 1 above, p. 185.

22 S A Julious and M A Mullee, 'Confounding and Simpson's paradox.' Brit. med. J., 1994, 309: 1480-1.
} 


\section{Maternal Mortality and Midwifery on the Isle of Man}

by blood transfusion, etc.), there are good reasons for believing that before that date the fluctuations of the maternal mortality rates on the Isle of Man and Loudon's plateaus were both determined almost entirely by changes in two independent variables, the health of the mothers and the quality of obstetric care. While the health of the mothers improved the maternal mortality rates would tend to fall. Similarly an improvement in the quality of the obstetric care would tend to depress the rates and, conversely, a fall in the quality of either determinant would tend to raise the MD/BR.

If the maternal mortality rates are to form a plateau these two independent variables must change so as to nullify each other's effects and thus the changes in one of the two must be detrimental. It is more likely that the improvement in the mothers' health had a benign effect and that the incursions by the doctors into the midwives' field had an adverse effect than that women became more liable to die in childbirth as they grew healthier. The data from the Isle of Man supports the first view, the adverse effect of the intervention by doctors being most obvious during the early 1920s. Thus it appears that fewer mothers would have died in childbirth in those countries where Loudon's plateaus are found if the doctors had left well alone instead of supplanting the midwives.

\section{APPENDIX A}

The following table is derived from the Registers of Death and sets out the maternal deaths on the Isle of Man from 1882 to 1961 , indicating where the death took place and giving the marital status and age at death of the mother and the registered causes of death.

\section{Abbreviations used in Appendices $A$ and $B$ :}

The number assigned to each case is given first. (In the text the case number is preceded by the number of the quinquennium ( $Q 1$ to $\mathrm{Q} 16)$ in which the case will be found.)

If the case number is followed by an asterisk * the case was probably represented in a Chief Registrar's annual report, if by an $\mathrm{x}$ it was an extra case found only in the Register of Death, if by HR the case was probably registered as a maternal death by the registrar but "hidden" in the Register of Death and if a maternal death has been hidden from the registrar the case number is followed by $\mathrm{H}$; e.g., Case Q1/19H.

The letter of the alphabet which follows next classifies the cause of death indicated on the Death Certificate as follows:

$A=a n$ Associated disease, now called an indirect death.

$B=$ puerperal Bleeding.

$\mathrm{C}=$ Convulsions/puerperal toxaemia.

$\mathrm{D}=$ Debility, asthenia, anaemia or exhaustion when not qualified.

$\mathrm{E}=$ Embolism/phlegmasia alba dolens and Ectopic pregnancy.

$\mathrm{F}=$ puerperal Fever and its synonyms.

I=Intervention.

$\mathrm{O}=$ all Other causes of death.

The letter of the alphabet which follows indicates where the death occurred:

$B=$ in a private nursing home.

$F=$ in the Fever Hospital

$\mathrm{H}=$ at the mother's home.

$\mathrm{M}=$ in the Jane Crookall Maternity Home. 


\section{G Pantin}

$\mathrm{N}=$ in Noble's Hospital.

$\mathrm{P}=$ in Home for the Poor or the Asylum.

R=in Ramsey Cottage Hospital.

Before 1927 all those who died in an institution were sent there as emergencies after getting into difficulties at home, with the exception of those who elected for delivery in a private nursing home. Many who died in the Jane Crookall Maternity Home were admitted as emergencies but as the years went by more and more mothers booked into the Home.

The code for the marital status of the women, which comes next, is as follows:

$M=$ married and living with husband.

$\mathrm{S}=$ separated from husband or widowed.

U=unmarried.

The age of the woman at death follows and then the causes of death as stated in the Registers of Death in the General Registry of the Isle of Man. Registration by the General Medical Council was not obligatory for a doctor on the Isle of Man until 1899 and before that date a death could be registered by "Some person present at the death, or in attendance during the last illness". When the death has not been certified by a doctor the cause of death is followed by the word, "Uncertified".

\section{Maternal Mortality 1882-1961}

A summary of each quinquennium follows the list of cases, DMD stands for the number of direct maternal deaths and $B$ for the number of births.

\section{The 1st Quinquennium, 1882-1886}

Deaths from three abortions were registered.

1x A.H.M.37. 1.Obstruction of bowels, 13 days. 2.Exhaustion from premature labour.

2H A.H.M.28. 1.Pulmonary consumption. 2.Syncope. (Death of son of above registered 4 months later as follows: 1 . Delicate from birth (mother dead).)

3* A.H.M.37. 1.Childbirth. 2.Anaemia. 3.Pneumonia, dropsy.

4* A.H.U.40. 1.Bronchitis 1 month. 2.Weakness after delivery.

5x A.H.M.27. 1.Phthisis pulmonalis. 2.Exhaustion after confinement.

6* A.H.M.33. 1.Heart disease; 5 years. 2.Dropsy (pregnancy).

3.Delivery at 8 months; syncope.

7x A.H.M.42. 1.Cold; bronchitis. 2.Hydrothorax or water on the chest after confinement.

8x A.H.U.21. 1.Pneumonia. 2.Premature confinement.

9* A.H.M.37. 1.Dilatation of heart. 2.Parturition, shock. 10x A.H.M.23. 1.Typhoid fever. 2.Premature labour.

11* B.H.M.32. 1.Placenta praevia. 2.Haemorrhages, 2 days.

12* B.H.M.46. 1.Premature confinement at 7 months. 2.Uterine haemorrhage, 8 minutes.

13x B.H.M.37. 1.Antenatum haemorrhage. 14* B.H.U.18. 1.Childbirth, 8 days. 2.Placenta praevia; haemorrhage. Uncertified.

15* B.H.U.38. 1.Childbirth, 4 days. 2.Placenta praevia with profuse haemorrhage.

16* B.H.M.31. 1.Delivery. 2.Secondary haemorrhage; syncope.

$17 *$ B.H.S.38. 1.Postpartum haemorrhage.

18* B.H.M.41 1.Parturition. 2.Placenta praevia; haemorrhage; exhaustion, 1 day.

19H C.H.M.28. 1.Albuminuria. 2.Exhaustion. (Death of son of above registered 3 weeks later as follows: 1.Delicate from birth (mother dead).)

20* C.H.M.27. 1.Puerperal mania; coma, 42 days. 
21HR C.H.U.24. 1.Uraemic convulsions for one day. 2.Coma for 2 hours.

22x C.H.M.28. 1.Albuminuria. 2.Parturition. Apoplexy.

23* C.H.M.32 . 1.Puerperal convulsions, 2 days.

24* C.H.M.29. 1.Puerperal convulsions, 24 hours.

25* D.H.M.41. 1.Exhaustion after confinement, 3 hours.

26* D.H.M.31 1. 1.Parturition, 18 days. 2.Asthenia.

27* D.H.M.44. 1.Exhaustion after childbirth. 28* E.H.M.22. 1.Parturition. 2.Embolism.

29* F.H.M.29. 1.Confinement. 2.Peritonitis. 30* F.H.U.21. 1.Puerperal metritis. 2.Diarrhoea.

31* F.H.M.24. 1.Childbirth. 2.Meningitis, 5 weeks (separated).

32x F.H.U.22. 1.Puerperal septicaemia, 14 days.

33x F.H.M.32. 1.Postpartum septicaemia.

34* F.H.U.20. 1.Puerperal peritonitis, 6 days.

35* F.H.M.22. 1.Puerperal peritonitis.

36* F.H.M.25. 1.Puerperal peritonitis.

37* F.H.M.21. 1.Puerperal peritonitis, 6 days.

38* F.H.M.26. 1.Puerperal fever, Uncertified.

39* F.H.M.45. 1.Puerperal fever, 4 days.

40x F.H.M.21. 1.Puerperal peritonitis, 2 days.

41x F.H.M.33. 1.Postpartum septicaemia, 4 days.

42HR F.H.M.30. 1.Inflammation of womb. Uncertified.

43* F.H.M.23. 1.Puerperal fever, 3 days. 44* F.H.U.35. 1.Puerperal fever. 2.Debility.

45x F.H.M.27. 1.Puerperal peritonitis.

46* F.H.M.32. 1.Puerperal peritonitis, 7 days.

47* F.H.U.24. 1.Childbirth. 2.Metritis.

48* I.H.M.40. 1.Childbirth. 2.Shock to her system consequent on inverted womb during confinement. Coroner

49* O.H.M.26. 1.Hysteria. 2.Premature birth. 3.Paraplegia, prostration.
50* O.H.M.32. 1.Vomiting from pregnancy, 2 months.

$51 *-57 *$ each registered as a death from "Childbirth". All died at home and were uncertified and are classed as $\mathbf{O}$.

1st Q 1882-1886:DMD 47: (A10), B8, C6, D3, E1, F19, I1, O9; B 7327; MD/BR 64.

\section{2nd Quinquennium 1887-1891}

Deaths from three abortions were registered. 1x A.H.M.40. 1.Impacted gall stones.

2.Premature confinement. 3.Exhaustion.

2x A.H.M.24. 1.Childbirth. 2.Typhoid fever.

3x A.H.M.20. 1.Childbirth. 2.Pneumonia.

4x.A.H.U.21. 1.Heart disease accelerated by her pregnancy.

5* A.H.M.30. 1.Dropsy, 9 months 2.Childbirth, 3 weeks. Uncertified.

6x A.H.M.26. 1.Parturition 2.Scarlet fever. Two of her children died of scarlet fever within ten days.

7x A.H.M.40. 1.Acute phthisis, 13 weeks. 2.Childbirth, 6 weeks.

8x A.H.M.42. 1.Haematemesis.

2.Premature birth.

9* A.H.M.38. 1.Natural causes.

2.Bronchitis and congestion of lungs after her recent confinement. Coroner.

10* B.H.M.24. 1.Confinement. 2.Accidental haemorrhage.

11* B.H.M.27. 1.Confinement, 23 days. 2.Secondary haemorrhage, exhaustion.

12* B.H.M.30. 1.Acute nephritis. 2.Placenta praevia.

13* B.H.M.36. 1.Confinement. 2.Harmorrhage.

14HR B.H.M.37. 1.Uterine haemorrhage, syncope. Uncertified. The informant was a medical man who was "in attendance at death" but he did not issue a death certificate. 


\section{G Pantin}

15* B.H.U.27. 1.Childbirth. 2.Placenta praevia.

16* B.H.M.37. 1.Placenta praevia. 2.Haemorrhage, exhaustion.

17* B.H.M.35. 1.Postpartum haemorrhage. 2.Exhaustion.

18* B.H.M.44. 1.Haemorrhage after confinement.

19HR B.H.M.40. 1.Uterine haemorrhage.

20* B.H.M.32. 1.Haemorrhage after confinement.

$21 *$ C.H.M.29. 1.Puerperal eclampsia. Exhaustion.

22* C.H.S.22. 1.Pregnancy. 2.Albuminuria, convulsions.

23x C.H.M.37. 1.Premature parturition. 2.Acute nephritis.

24* C.H.M.42. 1.Albuminuria. 2.Eclampsia, induced labour, coma.

25* C.H.M.35. 1.Puerperal convulsions.

26* C.H.M.33. 1.Puerperal convulsions, 2 days.

27x C.H.M.28. 1.Puerperal convulsions.

28* C.H.M.18. 1.Pregnancy; 8 months.

2.Tubular nephritis, eclampsia, 30 hours.

29x C.H.M.25. 1.Pregnancy at 7 to 8 months. 2.Secondary epilepsy, 31 hours.

30* C.H.M.41. 1.Parturition. 2.Convulsions.

31H C.H.U.24. 1.Eclampsia-qualified by an indecipherable word.

32* D.H.M.45. 1.Exhaustion after labour.

33* D.H.M.33. 1.Exhaustion after confinement.

34* F.H.M.32. 1.Puerperal fever, 8 days.

35* F.H.M.32. 1.Puerperal fever, 2 days. 2.Peritonitis.

36* F.H.M.29. 1.Puerperal fever, 4 days.

37* F.H.M.21. 1.Childbirth. 2.Acute peritonitis, 36 hours.

38* F.H.M.31. 1.Puerperal fever, 5 days.

39* F.H.M.19. 1.Childbirth, 14 days. 2.Puerperal fever, 9 days.

40* F.H.M.22. 1.Puerperal infection (after confinement), 4 weeks.

$41 *$ F.H.M.35. 1.Puerperal fever, 4 days.

42* O.H.M.38. 1.Confinement. 2.Syncope.

43* O.H.M.21. 1.Childbirth. Uncertified.
44* O.H.M.44. 1.Natural causes consequent upon childbirth.

2nd Q 1887-1891:DMD 35: (A9), B11, C11, D2, E0, F8, I0, O3; B 7608; MD/BR 46.

\section{3rd Quinquennium 1892-1896}

Deaths from four abortions were registered.

1x A.N.M.35. 1.Childbirth. 2.Capillary

bronchitis.

2* A.N.M.22. 1.Heart disease.

2.Parturition.

3* A.H.M.27. 1.Cardiac disease.

2.Parturition.

4* B.H.M.43. 1.Haemorrhage. 2.Placenta praevia.

5* B.H.M.38. 1.Childbirth.

2.Haemorrhage, syncope. Uncertified.

6* B.H.M.38. 1.Antepartum and postpartum haemorrhage.

7* B.H.M.32. 1.Antepartum haemorrhage.

8* C.H.M.35. 1.Childbirth. 2.Puerperal eclampsia.

9* C.H.M.25. 1.Puerperal eclampsia.

10x C.H.M.22. 1.Acute Bright's disease.

2.Premature parturition.

$11 *$ C.H.U.17. 1.Puerperal eclampsia.

12* C.N.M.27. 1.Pregnancy at 7 months.

2.Uraemia convulsions.

13* C.H.M.26. 1.Puerperal eclampsia.

14* C.H.M.34. 1.Puerperal convulsions, 48 hours.

15* C.H.M.25. 1.Puerperal convulsions, 1 day.

16* C.H.M.40. 1.Puerperal convulsions, 3 hours.

17* D.H.M.36. 1.Parturition. 2.Exhaustion.

18* D.H.M.24. 1.Confinement. 2.Exhaustion.

19x D.H.M.27. 1.Anaemia. 2.Parturition.

20* D.H.M.39. 1.Confinement.

2.Exhaustion, 4 hours.

21* D.H.M.40. 1.Parturition. 2.Exhaustion.

22* D.H.M.29. 1.Exhaustion after

confinement.

23* E.H.M.35. 1.Puerperal embolism.

24* E.H.M.26. 1.Puerperal thrombosis.

25x E.N.M.34. 1.Extrauterine gestation.

2.Peritonitis. 


\section{Maternal Mortality and Midwifery on the Isle of Man}

26* F.H.M.35. 1.Confinement. 2.Puerperal fever, 5 days.

$27 *$ F.H.M.32. 1.Confinement, 7 days. 2.Puerperal fever.

28x F.H.M.44. 1.Puerperal pyaemia, 12 days.

29* F.H.U.28. 1.Parturition, 9 days. 2.Puerperal peritonitis, 6 days.

30* F.H.M.38. 1.Parturition, 8 days. 2.Puerperal peritonitis.

31* F.H.M.24. 1.Puerperal fever. 2.Exhaustion.

32* F.H.M.20. 1.Parturition. 2.Puerperal septicaemia.

33x F.H.M.29. 1.Puerperal fever. 2.Septicaemia.

34x F.H.M.28. 1.Childbirth, 6 days. 2.Acute enteritis, 5 days.

3.Exhaustion.

35* F.H.M.20. 1.Childbirth, 10 days.

2.Puerperal fever, 5 days.

3.Exhaustion.

36* F.H.M.32. 1.Puerperal fever, 5 days.

37* F.H.M.40. 1.Peritonitis (puerperal).

38* F.H.M.29. 1.Parturition. 2.Puerperal septicaemia.

39* F.H.M.22. 1.Puerperal septicaemia, 5 days. 2.Pyrexia; exhaustion.

40* F.H.M.24. 1.Parturition. 2.Metritis, exhaustion.

41* F.H.M.35. 1.Puerperal peritonitis.

42* I.H.M.19. 1.Great shock to her system consequent to the womb being and remaining inverted after delivery of her child as ascertained by postmortem, the body having been exhumed to ascertain cause of her death, the jurors advised no blame could be attached to the nurse. Coroner.

43x O.H.U.21. 1.Angina pectoris. 2.Childbirth.

44x O.N.M.37. 1.Premature birth of child at 6 months.

45* O.H.M.42. 1.Confinement. 2.Heart failure.
46* O.H.M.22. 1.Childbirth. 2.Pulmonary \& renal congestion.

47H O.H.M.25. 1.Dilatation of heart. (Child born 13 days before mother's death.)

3rd Q 1892-1896: DMD 44: (A3), B4, C9, D6, E3, F16, I1, O5; B 7034 MD/BR 63.

4th Quinquennium 1897-1901

Death from one abortion registered.

1x A.H.M.32. 1.Childbirth (24 days ago). 2.Tuberculosis of lung.

2* A.H.M.30. 1.Morbus cordis. 2.Parturition; syncope.

3x A.H.M.44. 1.Acute pneumonia. 2.Parturition.

4x A.H.M.22. 1.Acute pneumonia 2.Parturition.

5x A.H.M.29. 1.Heart disease. 2.Influenza. 3.Premature confinement. 4.Pneumonia.

6* B.H.M.32. 1.Antepartum haemorrhage.

7* B.H.M.32. 1.Premature confinement. 2.Haemorrhage.

8* B.H.M.44. 1.Placenta praevia. 2.Confinement.

9* B.H.M.27 1.Anaemia. 2.Parturition; placenta praevia. Syncope.

10* B.H.M.38. 1.Postpartum haemorrhage. 2.Convulsions.

3.Exhaustion.

11* B.H.U.35. 1.Postpartum haemorrhage, 5 minutes.

12* B.H.M.34. 1.Placenta praevia, haemorrhage. 2.Confinement, PPH; syncope.

13* C.H.U.18. 1.Puerperal convulsions and exhaustion.

14* C.H.M.28. 1.Albuminuria. 2.Puerperal eclampsia.

15* C.H.M.24. 1.Parturition. 2.Convulsions.

16* C.H.M.27. 1.Uraemia. 2.Puerperal convulsions.

17* C.H.M.32. 1.Nephritis. 2.Pregnancy. 3.Uraemic convulsions.

18* D.H.U.33. 1.General debility. 2.Parturition.

19* D.H.M.36. 1.Exhaustion following confinement 2 weeks ago. 


\section{G Pantin}

20* E.H.M.42. 1.Parturition. 2.Thrombosis; pulmonary embolism; asphyxia.

21* E.H.M.32. 1.Phlegmasia Dolens following parturition. 2.Embolism of pulmonary artery.

$22 *$ E.H.M. 39. 1.Premature labour at 7 months. 2.Embolism of pulmonary artery 45 minutes after delivery.

23* E.N.M.28. 1.Extrauterine gestation, 2 months. 2.Haematocoele, 12 hours.

24* E.H.M.41. 1.Parturition. 2.Embolism of pulmonary arteries.

25* F.H.M.22. 1.Puerperal septicaemia.

26* F.F.M.39. 1.Puerperal septicaemia.

27* F.H.M.29. 1.Confinement, 22 days. 2.Meningitis, 14 days; exhaustion.

28* F.H.M.33. 1.Childbirth. 2.Peritonitis; exhaustion.

29* F.H.M.33. 1.Childbirth. 2.Puerperal fever.

30* F.H.U.21. 1.Puerperal fever. 2.Asthenia.

31 * F.H.M.37. 1.Puerperal fever, 5 days.

32* F.H.M.33. 1.Puerperal fever.

33* F.H.M.27. 1.Puerperal peritonitis.

34* F.H.M.36. 1.Puerperal septicaemia.

35* F.H.M.29. 1.Parturition. 2.Puerperal fever; septic pneumonia.

36* F.H.M.29. 1.Confinement. 2.Enteritis; heart failure.

37x O.H.M.38. 1.Vomiting of pregnancy, 14 days.

38* O.H.M.42. 1.Heart failure during confinement.

4th Q 1897-1901: DMD 33: (A5), B7, C5, D2, E5, F12, I0, O2; B 6898; MD/BR 48.

\section{5th Quinquennium 1902-1906}

Death from one abortion was registered. 1* A.H.M.28. 1.Pulmonary tuberculosis.

2.Childbirth 3 weeks; syncope. 2x A.H.M.28. 1.General tuberculosis.

2.Childbirth; exhaustion.

3* A.H.M.33. 1.Parturition. 2.Influenza; heart failure.

4* A.H.M.38. 1.Heart disease.

2.Confinement 3 days before death.

5* B.H.M.43. 1.Haemorrage following on her confinement.

6* B.H.U.23. 1.Postpartum haemorrhage, 48 hours; asthenia.

7* B.H.M.48. 1.Parturition.

2.Haemorrhage; syncope.

8* C.H.M.39. 1.Bright's Disease.

2.Childbirth; uraemia.

9* C.H.M.45. 1.Bright's disease.

2.Premature confinement.

10* C.H.M.25. 1.Puerperal eclampsia.

11* F.H.M.26. 1. Confinement (10 days ago). 2.Puerperal fever.

12* F.H.M.37. 1.Puerperal fever.

13x F.H.M.37. 1.Parametritis following confinement 24th day.

14* F.H.M.44. 1.Acute peritonitis. 2.Parturition.

15* F.H.U.17. 1.Childbirth. 2.Septicaemia. 16* F.H.M.29. 1.Puerperal fever, 8 days.

17* F.H.M.24. 1.Puerperal septicaemia.

18* F.H.M.35. 1.Puerperal Fever.

2.Exhaustion.

19* F.H.M.21. 1.Puerperal fever.

20* F.H.M.31. 1.Puerperal fever, 28 days.

21* F.H.M.40. 1.Puerperal Septicaemia; pneumonia.

22* O.H.M.38. 1.Cardiac syncope; shock. 2.Parturition.

23* O.H.M.30. 1.Puerperal mania. 2.Heart failure.

5th Q 1902-1906: DMD 19: (A4), B3, C3, D0, E0, F11, I0, O2; B 5935; MD/BR 32.

\section{6th Quinquennium 1907-1911}

No abortions were registered during the five years.

1x A.H.M.42. 1.Rheumatic fever.

2.Premature delivery; syncope. 


\section{Maternal Mortality and Midwifery on the Isle of Man}

2x A.H.M.26. 1.Pneumonia, 5 days.

2.Premature labour; heart

failure.

3* A.H.M.36. 1.Childbirth (Stillborn child). 2.Acute tonsillitis.

4* A.H.M.38. 1.Gastritis. 2.Parturition, exhaustion.

5* A.H.M.44. 1.Childbirth. 2.Influenza; coma.

6* A.H.M.34. 1.Goitre. 2.Parturition; syncope.

7* C.H.M.40. 1.Puerperal eclampsia.

8* C.H.M.30. 1.Puerperal eclampsia.

9* C.H.M.37. 1.Cardiac syncope.

2.Puerperal eclampsia.

10x C.H.M.37. 1.Nephritis. 2.Parturition; asthenia.

11x C.H.U.22. 1.Eclampsia. 2.Exhaustion.

12* C.H.M.31. 1.Premature labour.

2.Albuminuria; anasarca.

13* E.H.M.41. 1.Parturition, 16 days.

2.Pulmonary embolism.

14* E.H.M.30. 1.Childbirth, 21 days.

1.Phlegmasia dolens.

15* F.H.M.34. 1.Puerperal septicaemia.

16* F.H.M.37. 1.Pelvic cellulitis death 18 days after parturition.

17* F.H.U.33. 1.Childbirth. 2.Puerperal sepsis, 22 days.

18* F.H.M.37. 1.Parturition 6 days earlier.

2.Septicaemia.

19* O.H.M.28. 1.Premature labour. 2.Heart failure.

20* O.H.M.34. 1.Parturition, 8 days.

2.Meteorism; heart failure.

21* O.H.M.40. 1.Parturition. 2.Collapse.

6th Q 1907-1911: DMD 15: (A6), B0, C6, D0, E2, F4, I0, O3; B 5155; MD/BR 29.

\section{7th Quinquennium 1912-1916}

One abortion was registered during the five years.

1x A.H.M.39. 1.Bronchopneumonia, 33

days. 2.Childbirth

(premature labour), 31 days,

3.Septic endocarditis, 14 days. 2x A.H.M.37. 1.Cardiac hypertrophy.

2.Childbirth. (Labour

began 12.10 a.m. terminated

10.20 a.m.) male stillborn

child.

3* A.H.M.38. 1.Cardiac stenosis.

2.Childbirth 7 hours; cardiac failure, 10 mins.

4x A.H.M.39. 1.Mitral (Valvular disease); dropsy, 7 months.

2.Childbirth 7 days ago; syncope (heart failure).

5* A.H.M.31. 1.Mitral insufficiency.

2.Childbirth; cardiac failure.

6x A.H.M.23. 1.Valvular disease of the heart, mitral valve.

2.Childbirth 11 days; pneumonia, 6 days.

7* B.H.M.36. 1.Accidental haemorrhage (Pregnancy). 2.Syncope.

8* B.H.M.34 1.Placenta praevia.

2.Haemorrhage.

9x C.H.M.38. 1.Acute nephritis.

2.Parturition; heart failure.

10* C.H.M.44. 1.Childbirth. 2.Ulcer of stomach; nephritis; convulsions.

11* C.H.M.38. 1.Nephritis. 2.Parturition; uraemia.

12* C.H.M.33. 1.Nephritis. 2.Parturition; uraemia.

13* C.H.M.32. 1.Childbirth, 3 hours.

2.Eclampsia \& coma, 1 hour.

14* D.H.M.33. 1.Childbirth. 2.Syncope \& exhaustion.

15* E.H.M.34. 1.Myocarditis. 2.Pulmonary thrombosis 12 days after childbirth.

16* E.H.M.28. 1.Parturition. 2. Cardiac embolism; syncope.

17* F.H.M.32. 1.Puerperal fever. 2.Cardiac debility.

18* F.N.M.34. 1.Confinement. 2.Caesarian section; septicaemia.

19* F.N.M.35. Puerperal septicaemia.

20* F.H.M.33. 1.Childbirth, 25 days.

2.Puerperal septicaemia, 22 days.

21* O.P.U.41. 1.Parturition 


\section{G Pantin}

22* O.H.M.35. 1.Childbirth. 2.Failure of heart's action.

7th Q 1912-1916: DMD 16: (A6), B2, C5, D1, E2, F4, I0, O2; B 4252; MD/BR 38.

\section{8th Quinquennium 1917-1921}

No abortions were registered in the five years.
1x A.H.M.39. 1.Influenza.
2.(accouchement premature) pneumonia.

2x A.H.U.18. 1.Parturition. 2.Bronchitis; exhaustion.

3x A.H.M.28. 1.Pulmonary tuberculosis. 2.Childbirth.

4* A.H.M.29. 1.Hypertrophy of heart. 2.Childbirth (4 hours from beginning of labour).

5* A.H.M.38. 1.Hypertrophy of heart. 2.Confinement (labour not terminated).

6x A.H.M.31. 1.Tuberculosis of lungs. 2.Parturition. 3.Acute tuberculosis.

$7 *$ B.H.M.26. 1.Placenta praevia.

2.Postpartum haemorrhage; shock.

8* C.H.U.31. 1.Parturition. 2.Eclampsia.

9* C.N.M.24. 1.Albuminuria. 2.Puerperal eclampsia, $25 \mathrm{hrs}$ operation, $12 \mathrm{hrs} \mathrm{coma}$.

10* C.H.U.15. 1.Difficult labour. 2.Eclampsia.

11* C.H.M.27. 1.Uraemic poisoning \& dropsy. 2.Confinement followed by postpartum haemorrhage; heart failure.

12* D.H.M.36. 1.Debility, 2.Childbirth.

13x D.H.M.41. 1.Parturition. 2.Exhaustion.

14* E.H.M.30. 1.Childbirth 27 days.

2.Cardiac embolus sudden.

15* E.N.M.34. 1.Ruptured extrauterine gestation (peritoneal), 3 days. 2.Internal haemorrhage. operation (laparotomy), 3 days.

16* F.H.M.28. 1.Puerperal septicaemia. 17* F.H.M.40. 1.Puerperal septicaemia.
18* F.P.M.23. 1.Septic infection after childbirth. 2.Puerperal fever.

19* F.P.S.27. 1.Septicaemia puerperal.

20* F.N.M.29. 1.Puerperal pyaemia.

21* F.R.M.33. 1.Parturition. 2.Septicaemia.

22* F.H.M.28. 1.Puerperal septicaemia.

23* O.H.M.41. 1.Childbirth. 2.Shock.

24* O.H.M.22. 1.Shock from childbirth 2.Heart failure.

8th Q 1917-1921: DMD 18: (A6), B1, C4, D2, E2, F7, I0, O2; B 3608; MD/BR 50.

\section{9th Quinquennium 1922-1926}

One abortion was registered during the five years.

1* A.H.M.41. 1.Bronchitis.

2.Bronchopneumonia, 6 days; childbirth, 30 hours.

2* A.H.M.33. 1.Influenza 14 days. 2.Pneumonia 6 days; childbirth.

3* A.H.M.37. 1.Fatty degeneration of heart. 2.Childbirth, cardiac syncope.

4* B.H.M.25. 1.Placenta praevia. 2.Antepartum haemorrhage.

5* B.H.M.25. 1.Placenta praevia. 2.Uterine haemorrhage (antepartum), 10 days; exhaustion.

6* B.P.U.30. 1.Premature Labour. 2.Cervical metritis; uterine haemorrhage.

7* B.H.M.29. 1.Childbirth. 2.Postpartum haemorrhage.

8* B.N.M.38. 1.Placenta praevia; haemorrhage.

9* C.H.M.36. 1.Pregnancy; albuminuria. 2.Premature birth of child. 3.Uraemia.

10* C.H.M.20. 1.Anaemia. 2.Nephritis of pregnancy; cardiac failure following pregnancy.

$11 *$ C.N.M.34 1.Pregnancy; albuminuria. 2.Uraemia.

12* C.H.M.31 . 1.Puerperal convulsions. 2.Coma.

13x C.H.M.32. 1.Pre-eclamptic toxaemia, 2 months. 2.Cerebral haemorrhage, 2 days. 
14* C.N.U.15. 1.Eclampsia following on childbirth the result of natural causes. Coroner.

15* C.N.M.25. 1.Eclampsia, 12 hours.

16* E.N.M.25. 1.Ectopic gestation, 3 months. 2.Rupture, 16 days; operation, 14 hours.

17* E.B.M.38. 1.Pulmonary embolism; puerperal.

18* E.B.M.31. 1.Ruptured ectopic gestation. 2.Haemorrhage.

19* F.N.M.30. 1.Puerperal septicaemia.

20* F.B.M.35. 1.Puerperal septicaemia.

$21 *$ F.N.U.33. 1.Puerperal septicaemia

2.Acute pleurisy.

22* I.N.M.25. 1.Rupture of uterus during childbirth (instrumental).

2.Fibrosis of uterus; operation removal of uterus.

23* I.H.M.36. 1.Accouchement. 2.Ruptured uterus; shock.

24* I.H.M.30. 1.Shock. 2.Difficult labour (instrumental).

25x I.H.M.31. 1.Childbirth. 2.Chloroform anaesthesia. 3.Sudden syncope.

26* O.H.M.43. 1.Difficult labour. 2.Shock.

$27 *$ O.H.M.32. 1.Parturition. 2.Abdominal distension acute cardiac failure.

28* O.N.M.22. 1.Persistent vomiting of pregnancy. 2.Operation, emptying of uterus; exhaustion.

9th Q 1922-1926: DMD 25: (A3), B5, C7, D0, E3, F3, I4, O3; B 3953; MD/BR 63.

\section{0th Quinquennium 1927-1931}

Two abortions were registered during the five years. 1929 was the first year without a maternal death on the Island.

\begin{tabular}{|c|c|}
\hline 1* B.H.M.30. & $\begin{array}{l}\text { 1.Antepartum haemorrhage. } \\
\text { 2.Shock. }\end{array}$ \\
\hline x C.H.M.25. & $\begin{array}{l}\text { 1.Cardiac failure. } \\
\text { 2.Eclampsia. }\end{array}$ \\
\hline * C.M.M & 1.Eclampsia. \\
\hline & $\begin{array}{l}\text { 1.Anaemia. 2.Parturition; } \\
\text { syncope. }\end{array}$ \\
\hline
\end{tabular}

5* F.H.M.39. 1.Puerperal pyaemia. 2.Phlebitis.

6* F.N.U.34. 1.Puerperal septicaemia.

7* I.H.M.30. 1.Ruptured uterus.

2.Accidental haemorrhage (full-term pregnancy).

8* O.H.M.29. 1.Collapse following long ineffectual labour. Coroner.

10th Q 1927- DMD 8: (A0), B1, C2, D1, 1931: E0, F2, I1, O1; B 3422; MD/BR 23.

\section{1th Quinquennium 1932-1936}

Three abortions were registered during the five years.

1* B.H.M.39. 1.Uterine haemorrhage (Placenta praevia).

2* B.N.M.24. 1.Postpartum haemorrhage.

3* B.M.M.26. 1.Postpartum haemorrhage.

4* B.H.M.30. 1.Postpartum haemorrhage.

5* C.H.M.24. 1.Puerperal eclampsia.

6* C.H.M.43. 1.Heart failure. 2.Eclampsia of pregnancy.

7* F.N.M.21. 1.Septicaemia. 2.Puerperal sepsis.

8* F.H.U.20. 1.Puerperal hyperpyrexia.

2.Toxaemia, syncope.

9* F.H.M.34. 1.Cerebral toxaemia. 2.Puerperal infection.

11th Q 1932- DMD 9: (A0), B4, C2, D0, 1936 E0, F3, I0, O0; B 3273; MD/BR 27.

\section{2th Quinquennium 1937-1941}

Three abortions were registered during the five years.

1x A.N.M.34. 1.Bronchopneumonia.

2.Premature labour.

2* B.N.M.40. 1.Haemorrhage. 2.Retained placenta. (1937)

3* B.H.M.20. 1.Postpartum haemorrhage.

2.Placenta praevia. (1937)

4* B.H.M.37. 1.Postpartum haemorrhage. (1938)

5@ B.M.M.26. 1.Cortical necrosis of kidneys. (9.8.1939) (Hidden antepartum haemorrhage). 


\section{G Pantin}

6* C.M.M.25. 1.Eclampsia. (1938)

7x C.H.M.39. 1.Uraemia. 2.Acute nephritis. 3.Pregnancy. (1937)

8* C.H.M.27. 1.Toxaemia of pregnancy. 2.Myocardial degeneration. (1937)

9@ C.M.U.26. 1.Acute oedema of lungs. 2.Eclampsia. (25.9.1939)

10* C.M.M.32. 1.Uraemia. 2.Renal. 3.Toxaemia of pregnancy. (1941)

11* E.B.M.33. 1.Pulmonary embolism. 2.Childbirth 32 days ago. (1941)

12@ F.H.U.26. 1.Puerperal septicaemia. 2.Acute bronchitis. (Had a live baby 25.9 .1940 and mother died 10.11.1940.)

13@ O.H.M.33. 1.Cardiac syncope. 2.Uterine inertia; prolonged labour. (Died April 1939.)

14@ O.H.M.34. 1.Shock. 2.Hydramnios and adherent placenta. 3.Pregnancy. (1940)

@ These cases occurred in 1939 or 1940 when no Annual reports were published.

12th Q 1937- $\quad$ DMD 13: (A1), B4, C5, D0, 1941: $\quad$ E1, F1, I0, O2; B 3558; MD/BR 37.

\section{3th Quinquennium 1942-1946}

Four abortions were registered during the five years.

1x A.H.M.31. 1.Mitral stenosis
2.Pregnancy.

2* B.M.M.32. 1.Shock and haemorrhage.

2.Placenta praevia.

3* B.H.U.23. 1.Cardiac muscle failure, shock. 2.Postpartum haemorrhage.

4* C.M.M.37. 1.Eclampsia.

5* C.M.M.24. 1.Eclampsia.

6x E.N.M.36. 1.Pulmonary embolism. 2.Phlegmasia alba dolens following parturition.
7* F.N.M.21. 1.Acute cardiac failure, toxaemia, endocarditis. 2.Postpartum debility. (Son registered by mother 19.3.1943. Mother died 22.6.1943.)

8* F.N.S.35. 1.Toxaemia, pelvic peritonitis. 2.Childbirth (12.9.45, stillbirth. Died 18.'12.45.)

13th Q 1942- DMD 7: (A1), B2, C2, D0, 1946: E1, F2, I0, O0; B 4112; MD/BR 17.

\section{4th Quinquennium 1947-1951}

One abortion was registered during the five years.

1x A.N.M.29. 1.Cardiac failure; mitral stenosis. 2.Postpartum.

2* B.M.M.40. 1.Peripheral circulatory failure. 2.Postpartum haemorrhage following normal birth.

3* B.N.M.30. 1.Postpartum Haemorrhage. 2.Cardiac failure, shock.

4* C.N.M.28. 1.Eclampsia, parturition. 2.Caesarian section, death 3 hours later.

5x E.M.M.29. 1.Pulmonary embolus following childbirth.

6x E.R.M.37. 1.Syncope, asthma. 2.Operation for ectopic pregnancy.

7* E.N.M.31. 1.Shock. 2.Haemorrhage. 3.Ruptured ectopic pregnancy.

8* I.N.M.35. 1.Cardiac failure \& shock. 2.Internal bleeding. 3.Rupture of gravid uterus.

14th Q 1947- DMD 7: (A1), B2, C1, D0, 1951: E3, F0, I1, O0; B 4316; MD/BR 16.

\section{5th Quinquennium 1952-1956}

No abortions were registered during the five years.

1* B.M.M.34. 1.Secondary obstetric shock.

2.Precipitate labour.

Postmortem: necrotic pituitary gland. 


\section{Maternal Mortality and Midwifery on the Isle of Man}

\begin{tabular}{|c|c|c|c|}
\hline * C.M.M.29. & $\begin{array}{l}\text { Admitted with toxaemia. } \\
\text { 1.Spontaneous stoppage of } \\
\text { heart following well }\end{array}$ & \multicolumn{2}{|c|}{$\begin{array}{l}\text { 16th Quinquennium 1957-1961 } \\
1957,1958,1960 \text { \& } 1961 \text { no maternal deaths } \\
\text { in summaries nor in Tables. }\end{array}$} \\
\hline * C.R.M.39. & $\begin{array}{l}\text { conducted labour. Coroner. } \\
\text { 1.Eclampsia, pregnancy. } \\
\text { 2.Caesarian section, delivery. }\end{array}$ & 1x A.N.M.26 & $\begin{array}{l}\text { 1.Intestinal obstruction, } \\
\text { mesenteric volvulus. } \\
\text { 2.Caesarian section. }\end{array}$ \\
\hline $\begin{array}{l}\text { 5th Q } 1952 \\
756:\end{array}$ & $\begin{array}{l}\text { DMD 3: (A0), B1, C2, D0, } \\
\text { E0, F0, I0; B 3397; MD/BR } 9 .\end{array}$ & $\begin{array}{l}\text { 16th Q } 195 \\
\text { 1961: }\end{array}$ & MD 0: B $3281 ;$ \\
\hline
\end{tabular}

\section{APPENDIX B \\ Data from the Jane Crookall Maternity Home Maternal Deaths 1927 to 1946}

[Q10/3]1931. Eclamptic, age 35, admitted from village 8 miles distant, 7 months gestation, lavage of stomach and colon, 4 pints of saline given, had 27 fits after admission, died 4 days after the delivery of a live baby weighing 3lbs 6ozs. 1. Eclampsia.

[Q11/3]1933. Mother aged 26 years. From Douglas. 2 stillbirths. Admitted 6.30 a.m. full term stillbirth $9 \mathrm{lbs}$ in weight born as a breech at 8.30 a.m., PPH, mother collapsed 9.20 a.m. Died 10.30 a.m. 1. Postpartum haemorrhage.

[Q11/6]1936. Eclamptic, age 43, primipara. From village 8 miles distant. 5 eclamptic fits, "Stomach washout, colon lavage $\&$ linseed poultices frequently", died before delivery on day of admission of 1. Heart failure. 2. Eclampsia of pregnancy.

[Q12/5]1939. APH. Admitted in a collapsed condition from Douglas, age 26, bleeding severely, vagina packed with gauze, delivered of a $2 \mathrm{lb} 4 \mathrm{oz}$ stillbirth, placenta broken up with normal loss. Albuminuria. Died 4th day. Death cert. 1. Cortical necrosis. No mention of childbirth.

[Q12/6]1938. Eclamptic, age 25, sent in unconscious from village 16 miles distant, 8 months gestation, 21 fits, delivered of 5lbs stillbirth, died on second day.

[Q12/9]1939. Certified as dying at J.C.M.H. but died before death entered in midwives' register. An unmarried woman aged 26 of no occupation from a village 16 miles distant. 1.(a) Acute oedema of lungs. 2. (b) Eclampsia.

[Q12/10]1941. Mother, aged 32, with one previous pregnancy, at 35 weeks gestation sent from town 16 miles distant with marked albuminuria, admitted 8.20 a.m. Delivered of a stillbirth at 11.45 a.m. same morning, mother died 3rd day. 1(a) Uraemia. (b) Renal. 2. Toxaemia of pregnancy.

[Q13/4]1942. A visitor and a primipara, aged 37 admitted from Douglas after a fit with marked albuminuria, delivered on 4th day of a stillbirth after A.R.M., placenta retained, removed manually, died 10 days later. 1 . Eclampsia.

[Q13/2]1943. APH, age 32, sent in by Douglas doctor at 8 a.m., lateral placenta praevia, blood plasma one pint given and glucose \& saline intravenously, delivered 2.45 p.m. of a stillborn, placenta expelled, collapsed, died 6.25 p.m. same day. 1. Shock and haemorrhage. 2. Placenta praevia.

[Q13/5]1944. Certified as dying at J.C.M.H. but not in midwives' register. Presumably died before her name could be entered in the register. Age 24. Husband in Army. 1. Eclampsia. 


\section{G Pantin}

Statistics derived from the Registers of the Midwives of the Jane Crookall Maternity Home 1927 to 1961.

\begin{tabular}{|c|c|c|c|c|c|c|c|}
\hline Quinquennium & 10 & 11 & 12 & 13 & 14 & 15 & 16 \\
\hline First year in quinquennium & 1927 & 1932 & 1937 & 1942 & 1947 & 1952 & 1957 \\
\hline $\begin{array}{l}\text { Number of mothers admitted } \\
\% \text { of all Island births }\end{array}$ & 556 & 752 & 1505 & 2080 & 3157 & 2830 & 3011 \\
\hline $\begin{array}{l}\text { delivered in Home } \\
\% \text { of the mothers admitted }\end{array}$ & 15 & 22 & 42 & 49 & 72 & 82 & 91 \\
\hline $\begin{array}{l}\text { who had twins } \\
\% \text { of the mothers admitted }\end{array}$ & 0.7 & 0.9 & 1.1 & 1.2 & 1.1 & 1.0 & 1.2 \\
\hline as emergencies & 5.9 & 4.9 & 1.9 & 2.9 & & & \\
\hline $\begin{array}{l}\% \text { of the mothers who had: } \\
\text { stillbirths }\end{array}$ & 8.1 & 5.6 & 5.8 & 4.4 & 2.6 & 24 & 23 \\
\hline toxaemia & 6.3 & 3.3 & 2.6 & 2.2 & 0.9 & 2.0 & 4.4 \\
\hline phlebitis & 0.5 & 1.6 & 0.2 & 0.1 & 0.2 & 0.2 & 0.1 \\
\hline postpartum bleeding & 6.3 & 8.5 & 9.0 & 8.3 & 7.7 & 4.3 & 0.9 \\
\hline ergometrine & & & & & 20 & 54 & 89 \\
\hline episiotomies & 1.8 & 1.9 & 4.2 & 3.2 & 4.0 & 8.2 & 12.3 \\
\hline forceps applied & 7.4 & 6.3 & 8.6 & 7.4 & 4.5 & 4.6 & 5.1 \\
\hline suturing & 31.1 & 34.6 & 32.6 & 29.4 & 25.2 & 26.4 & 30.2 \\
\hline inductions & 4.0 & 4.3 & 6.2 & 11.9 & 4.6 & 5.8 & 4.9 \\
\hline blood given & & & & & 0.2 & 1.4 & 0.8 \\
\hline Caesarian sections & \multicolumn{7}{|c|}{$\longleftrightarrow$ elective $\longrightarrow$ emergency increasingly } \\
\hline$\%$ of live births & 0.1 & 0.5 & 1.0 & 1.2 & 2.0 & 4.7 & 5.7 \\
\hline
\end{tabular}

